\title{
Floristic study of Byeonsanbando National Park in Korea
}

\section{Hyosun LEEM, Seahee HAN ${ }^{1}$, Hyun-Do JANG ${ }^{2}$, Yoon-Young KIM ${ }^{3}$ and Soonku SO ${ }^{4 *}$}

\author{
Forest Restoration Support Division, Baekdudaegan National Arboretum, Bonghwa 26209, Korea \\ ${ }^{1}$ National Agrobiodiversity Center, National Academy of Agricultural Science RDA, Jeonju 54875, Korea \\ ${ }^{2}$ Plant Resources Division, National Institute of Biological Resources, Incheon 22689, Korea \\ ${ }^{3}$ Department of Variety Examination, National Forest Seed \& Variety Center, Chungju 27495, Korea \\ ${ }^{4}$ Korea National Park Research Institute, Korea National Park Service, Wonju 26441, Korea \\ (Received 6 July 2020; Revised 5 October 2020; Accepted 23 November 2020)
}

\begin{abstract}
This study of vascular plants was conducted over a period of 33 days from March to October of 2018 in Byeonsanbando National Park, South Korea. Based on voucher specimens and photographs, 829 taxa in total were recorded, including 141 families, 458 genera, 748 species, 16 subspecies, 59 varieties, and 6 forma. Two endangered taxa were identified, Iris koreana Nakai and Saururus chinensis (Lour.) Baill. Five rare taxa were found, including Abeliophyllum distichum Nakai and Hypodematium glanduloso-pilosum (Tagawa) Ohwi. A total of 17 Korean endemic plants were investigated. Examples include Elsholtzia byeonsanensis M. Kim, Eranthis byunsanensis B. Y. Sun, and Lycoris flavescens M. Kim \& S. T. Lee. Of floristic regional indicators (third to fifth degree), 52 taxa were identified. Naturalized plants were identified, which included 79 taxa, and 7 species of ecosystem disturbance plants, such as Ambrosia artemisiifolia L., Lactuca serriola L., and Solidago altissima L. were found. We recorded 39 taxa of the plants vulnerable to climate change.
\end{abstract}

Keywords: Byeonsanbando National Park, flora, endangered and rare plants, endemic plants, naturalized plants

국립공원은 자연생태계의 보고인 국가생물핵심보전지 역으로 International Union for Conservation of Nature (IUCN)의 범주와 평가 기준에 따라 작성된 국가 적색목록 멸종우려종(threatened species)의 56.3\%가 분포하는 동·식 물의 핵심 서식지라고 할 수 있다(So et al., 2016). 이 중 19 호로 지정된 변산반도국립공원은 산과 바다가 공존하는 반도형 공원으로 1988년도에 도립공원에서 국립공원으 로 승격되었다. 전체 면적은 $153.9 \mathrm{~km}^{2}$ 로 육상면적은 $136.7 \mathrm{~km}^{2}(88.8 \%)$, 해상면적은 $17.2 \mathrm{~km}^{2}(11.2 \%)$ 를 차지하 고 있다(Yuk and Park, 2019). 행정구역상으로는 전라북도 부안군 변산면, 보안면, 상서면, 진서면, 하서면에 걸쳐 있 으며, 경·위도상 북위 $34^{\circ} 21^{\prime}-34^{\circ} 47^{\prime}$, 동경 $126^{\circ} 37^{\prime}-126^{\circ} 44^{\prime}$ 에 위치한다. 변산반도국립공원은 최고봉인 의상봉 $(508 \mathrm{~m})$ 을 중심으로 북동쪽으로 옥녀봉 $(354 \mathrm{~m})$, 남동쪽에 삼예봉 $(354 \mathrm{~m})$, 상여봉 $(398 \mathrm{~m})$, 옥녀봉 $(432 \mathrm{~m})$, 남쪽에 세봉 $(402 \mathrm{~m})$, 남서쪽에 쌍선봉 $(459 \mathrm{~m})$, 갑남산 $(408 \mathrm{~m})$, 신선봉 $(488 \mathrm{~m})$, 갈마봉 $(484 \mathrm{~m})$ 등 해발 $500 \mathrm{~m}$ 이내의 낮은 구릉성 산지가 위치한다. 중앙에는 부안호가 자리하고 있으며,
진서면 석포리에서 발원하는 직소천은 변산면 중계리, 부 안호, 대항리를 거쳐 서해로 합류한다.

부안군의 최근 30 년간 연평균 기온은 $12.6^{\circ} \mathrm{C}$, 연평균 최 고기온과 최저기온은 각각 $18.0^{\circ} \mathrm{C}$ 와 $8.0^{\circ} \mathrm{C}$, 연평균 강수량 은 $1,250.4 \mathrm{~mm}$ 로 기록되어 있다(Korea Meteorological Administration, 2019). 한반도 식물의 지리적 분포를 바탕 으로 구분된 8개의 식물구계 중 남부아구에 속하며(Lee and Yim, 2002), 한반도 기후를 바탕으로 구분한 산림식물 대 중 온대남부에 위치한다(Lim and Lee, 1999). 또한 변산 반도국립공원 내에는 도청리의 호랑가시나무 군락이 천 연기념물 제 122 호, 격포리의 후박나무 군락이 제 123 호, 중 계리의 꽝꽝나무 군락은 제124호, 미선나무 군락은 제 370 호로 각각 지정되어 있다(Cultural Heritage Administration, 2000).

변산반도국립공원의 식물상 연구는 Jeom (1990)이 119 과 698분류군, Sun et al. (1995)이 117과 686분류군, Oh (1999)는 118과 721분류군을 보고하였으며, Yang et al. (2009)은 123 과 721 분류군에 대한 구체적 목록을 제시하

\footnotetext{
*Author for correspondence: ssk822@knps.or.kr
} 
였다. 한편 변산반도국립공원 내 특정지역을 대상으로 이 루어진 소규모 식물상 연구에 따르면 소쩍골 주변 135분 류군(Oh et al., 2008), 작은당 일대 105분류군(Oh and Beon, 2009), 하섬 일대 235분류군(Oh et al., 2011a), 노랑붓꽃과 붉노랑상사화 자생지에 관한 연구에서 147 분류군(Oh et al., 2011b), 노랑붓꽃 자생지 연구에서 255 분류군(Oh, 2017)의 분포를 제시한 바 있다.

본 조사는 국립공원공단에서 실시한 2018년도 제 3 기 국 립공원 자연자원조사의 일환으로 수행되었으며, 변산반 도 국립공원에 분포하는 식물자원에 대한 보다 면밀한 조 사를 통하여 향후 변산반도국립공원 식물자원의 보전·관
리방안을 수립하기 위한 기초자료로 활용하는 데 그 목적 이 있다.

\section{재료 및 방법}

본 조사는 변산반도국립공원 전체를 대상으로 하였으 며, 2018년 3월부터 10월까지 총 33일에 걸쳐 조사를 수행 하였다(Fig. 1, Table 1). 결과의 정확성을 위해 현장에서 관 찰한 모든 식물을 대상으로 검색형질에 유용한 꽃, 열매, 포자 등의 세부형질을 촬영하였으며(Nikon D5300 + AF-S 40 mm Macrolens, Tokyo, Japan; Nikon D5300 + AF 105 mm
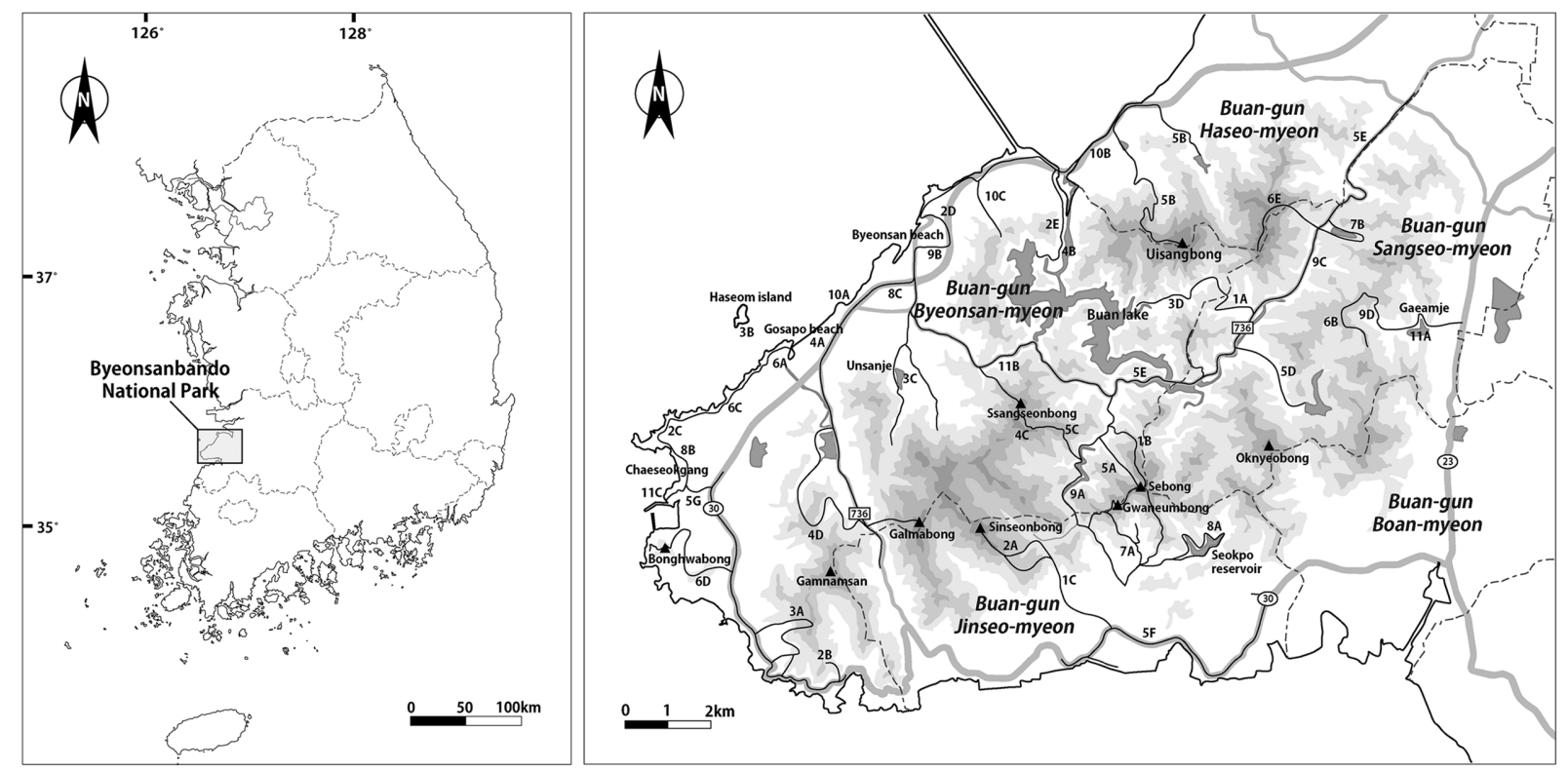

Fig. 1. Investigated area and routes of Byeonsanbando National Park.

Table 1. Investigation dates and routes of Byeonsanbando National Park.

\begin{tabular}{cll}
\hline \hline No. & \multicolumn{1}{c}{ Date } & \multicolumn{1}{c}{ Investigation route } \\
\hline 1 & $9-11$ Mar 2018 & A: Cheongnim-ri (Cheongnim village) \\
& & B: Junggye-ri (Naebyeonsan park information center $\rightarrow$ Sebong) \\
& C: Jinseo-myeon (Seokpo 2-gil $\rightarrow$ Sinseongol) \\
& & A: Seokpo-ri (Maegokjae $\rightarrow$ Sinseonbong $\rightarrow$ Sinseongol) \\
& B: Docheong-ri (Horanggasinamu community) \\
& C: Gyeokpo-ri (Hubaknamu community) \\
& D: Daehang-ri (Bangpoje $\rightarrow$ Eoryonggol) \\
& E: Junggye-ri (Buandaem-ro) \\
& A: Byeonsan-myeon (Gamnamsan) \\
& B: Byeonsan-myeon (Haseom island) \\
& C: Unsan-ri (Unsanje) \\
& & D: Gusigol (Cheongnim-ri $\rightarrow$ Junggye-ri $\rightarrow$ Buan lake) \\
& & A: Byeonsan-myeon (Gosapo beach) \\
& & B: Junggye-ri (Buandaem-ro) \\
& C: Byeonsan-myeon (Namyeochi parking area $\rightarrow$ Wolmyeongam) \\
& D: Byeonsan-myeon (Gamnamsan) \\
&
\end{tabular}


Table 1. Continued.

\begin{tabular}{|c|c|c|}
\hline No. & Date & Investigation route \\
\hline 5 & 15-17 Jun 2018 & $\begin{array}{l}\text { A: Junggye-ri (Naebyeonsan park information center } \rightarrow \text { Sebong) } \\
\text { B: Baengnyeon-ri (Munsuje) } \\
\text { C: Byeonsan-myeon (Wolmyeongam) } \\
\text { D: Sangseo-myeon (Geoseok bridge) } \\
\text { E: Naebyeonsan-ro } 736 \text { road } \\
\text { F: Byeonsan-ro } 30 \text { road } \\
\text { G: Byeonsan-myeon (Chaeseokgang) }\end{array}$ \\
\hline 6 & 20-22 Jul 2018 & $\begin{array}{l}\text { A: Byeonsan-myeon (Gosapo beach) } \\
\text { B: Sangseo-myeon (Gaeamsa temple } \rightarrow \text { Ugeumam) } \\
\text { C: Mapo-ri (Seongcheon } 1 \text { bridge) } \\
\text { D: Gyeokpo-ri (Bonghwabong) } \\
\text { E: Cheongnim-ri (Soeppulbawi route) }\end{array}$ \\
\hline 7 & 3-5 Aug 2018 & $\begin{array}{l}\text { A: Jinseo-myeon (Naesosa temple) } \\
\text { B: Cheongnim-ri (Ganeungol reservoir) }\end{array}$ \\
\hline 8 & $\begin{array}{l}31 \text { Aug } 2018 \\
1-2 \text { Sep } 2018\end{array}$ & $\begin{array}{l}\text { A: Jinseo-myeon (Seokpo reservoir) } \\
\text { B: Gyeokpo-ri (Chaeseokgang Masil-gil } \rightarrow \text { Gyeokpohaebyeon-ro) } \\
\text { C: Byeonsan-myeon (Unsanje Byeonsan beach) }\end{array}$ \\
\hline 9 & 28-30 Sep 2018 & $\begin{array}{l}\text { A: Naesosa temple } \rightarrow \text { Gwaneumbong } \rightarrow \text { Sebong } \rightarrow \text { Naesosa temple } \\
\text { B: Daehang-ri (Bangpoje) } \\
\text { C: Cheongnim-ri (Cheongnimje } \rightarrow \text { Nojeok-gil, Ganeungol reservoir) } \\
\text { D: Gamgyo-ri (Gaeamsa temple) }\end{array}$ \\
\hline 10 & $12-14$ Oct 2018 & $\begin{array}{l}\text { A: Byeonsan-myeon (Gosapohaebyeon) } \\
\text { B: Byeonsan-myeon (Jakso bridge } \rightarrow \text { Byeonsan bridge } \rightarrow \text { Saemangeum bridge) } \\
\text { C: Byeonsan-myeon (Byeonsan beach } \rightarrow \text { Jongam-gil) }\end{array}$ \\
\hline 11 & $24-26$ Oct 2018 & $\begin{array}{l}\text { A: Gamgyo-ri (Gaeamje) } \\
\text { B: Jiseo-ri } \\
\text { C: Gyeokpo port }\end{array}$ \\
\hline
\end{tabular}

Macrolens), GPS 수신기(Nikon GP-1 \& GP-1A)를 장착하여 각 식물에 대한 좌표를 획득하였다. 또한, 증거표본을 제 작하여 국립공원연구원 표본실(NP)에 보관하였다. 분류 군의 동정은 Lee (1996), Lee (2003), Kim and Kim (2011) 등 의 도감을 이용하였고, 양치식물은 Korean Fern Society (2005), Park et al. (2008), Lee and Lee (2015), 벼과와 사초 과는 Park et al. (2011), Cho et al. (2016)의 문헌을 참고하였 으며, 몇몇 식물에 대해서는 최근 국내외 학술지에 발표 된 논문을 참고하였다.

식물목록의 배열은 Engler의 분류체계를 기본으로 하되, 양치식물은 Christenhusz et al. (2011)의 분류체계를 따랐으 며, 학명은 국가표준식물목록(Korea National Arboretum, 2017)을 따랐으나, 일부는 국가생물종목록집(National Institute of Biological Resources, 2019)을 참조하였다. 아울 러, 멸종위기야생식물(Ministry of Environment, 2017), 희귀 식물(National Institute of Biological Resources, 2012), 한반 도 고유식물(Chung et al., 2017), 식물구계학적 특정식물 (Kim et al., 2018), 귀화식물(Park, 2009; Lee et al., 2011) 및 생태계교란야생식물(Ministry of Environment, 2019), 기후 변화 취약 산림식물(Oh et al., 2010; Oh et al., 2013)과 유용 자원식물(Korea Forest Service, 2014) 등을 파악하였다.

\section{결과 및 고찰}

\section{관속식물의 종조성}

본 연구에서 확인된 변산반도국립공원 일대의 관속식물 은 141 과 458 속 748 종 16 아종 59변종 6품종의 총 829 분류군 으로 조사되었다. 양치식물은 29 분류군 $(3.5 \%)$, 나자식물은 12 분류군 $(1.5 \%)$ 이었으며, 피자식물의 쌍자엽식물은 600 분 류군(72.3\%), 단자엽식물은 188 분류군 $(22.7 \%)$ 으로 확인되 었다(Fig. 2A, Table 2). 이는 한반도 관속식물 4,498분류군 (Korea National Arboretum, 2017)의 $18.4 \%$ 에 해당하였다. 과 별 종구성에 의한 다양성은 국화과가 97 분류군 $(11.7 \%)$ 으로 가장 높은 비율을 나타냈으며, 벼과 82 분류군 $(9.9 \%)$, 콩과 45분류군(5.4\%), 장미과 39분류군(4.7\%), 사초과 36 분류군 (4.3\%), 백합과 24 분류군(2.9\%) 순으로 확인되었다(Fig. 2B). 조사된 목록 중 재배 또는 식재종으로 판단되는 식물은 개 잎갈나무[Cedrus deodara (Roxb. ex D. Don) G. Don], 골담초 [Caragana sinica (Buc'hoz) Rehder], 두충(Eucommia ulmoides Oliv.), 모감주나무(Koelreuteria paniculata Laxm.), 사방오리 (Alnus firma Siebold \& Zucc.), 삼나무[Cryptomeria japonica (Thunb. ex L. f.) D. Don], 앵도나무(Prunus tomentosa Thunb.), 옻나무[Toxicodendron vernicifluum (Stokes) F. A. Barkley], 중국 
A
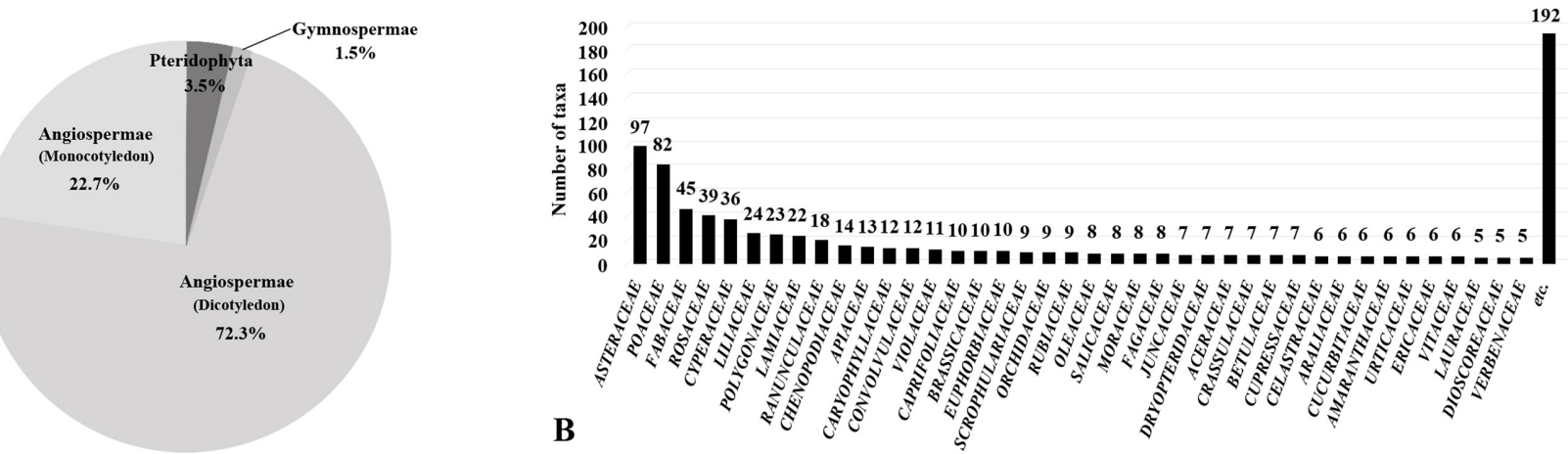

Fig. 2. The constitution rate of each plant group (A) and the constitution number of Family (B) in Byeonsanbando National Park.

Table 2. Summary on the floristics of Byeonsanbando National Park.

\begin{tabular}{lcccccccc}
\hline \hline \multicolumn{1}{c}{ Taxonomic rank } & Fam. & Gen. & Sp. & Subsp. & Var. & For. & Total & Ratio (\%) \\
\hline Pteridophyta & 15 & 19 & 28 & - & 1 & - & 29 & 3.5 \\
Gymnospermae & 3 & 9 & 12 & - & - & - & 12 & 1.5 \\
Angiospermae & 123 & 430 & 708 & 16 & 58 & 6 & 788 & 95.1 \\
$\quad$ Dicotyledon & 104 & 333 & 538 & 14 & 42 & 6 & 600 & 72.3 \\
Monocotyledon & 19 & 97 & 170 & 2 & 16 & - & 188 & 22.7 \\
\hline \multicolumn{1}{c}{ Total } & 141 & 458 & 748 & 16 & 59 & 6 & 829 & 100.0 \\
\hline
\end{tabular}
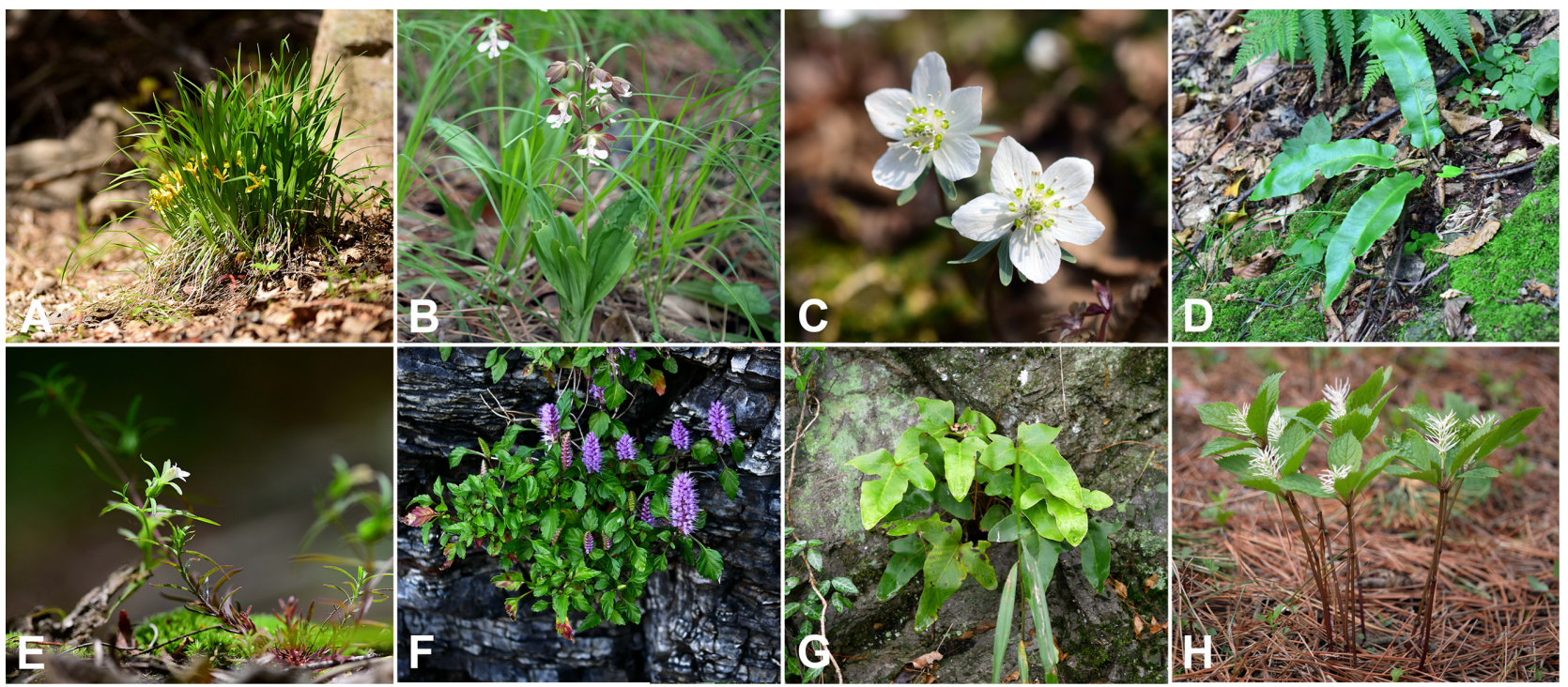

Fig. 3. Some remarkable taxa in Byeonsanbando National Park (A and $\mathbf{E}$ photograph by N. Y. Kim). A. Iris koreana Nakai. B. Calanthe discolor Lindl. C. Eranthis byunsanensis B. Y. Sun. D. Asplenium scolopendrium L. E. Monochasma sheareri (S. Moore) Maxim. ex Franch. \& Sav. F. Elsholtzia byeonsanensis M. Kim. G. Pyrrosia hastata (Houtt.) Ching. H. Chloranthus fortunei (A. Gray) Solms.

단풍(Acer buergerianum Miq.), 측백나무[Platycladus orientalis (L.) Franco], 탱자나무 [Poncirus trifoliatus (L.) Raf.], 회화나무 (Sophora japonica L.) 등 89분류군으로 전체 분류군 중 $10.7 \%$ 를 차지하였으며, 자생종과 구분하기 위해 관속식물목록 (Appendix 1)의 국명 뒤에 별표(*)로 표시하였다.

\section{멸종위기식물}

멸종위기야생생물 II급(Ministry of Environment, 2017)에 해당하는 식물로는 노랑붓꽃(Iris koreana Nakai), 삼백초 [Saururus chinensis (Lour.) Baill.] (식재) 등 2분류군이 확인 되었다(Table 3). 노랑붓꽃(Fig. $3 \mathrm{~A}$ )은 전라북도 정읍시 입 
Table 3. The list of endangered plants in Byeonsanbando National Park.

\begin{tabular}{ccccc}
\hline \hline No. & Family name & Scientific name & Korean name & Criteria \\
\hline 1 & Saururaceae & Saururus chinensis (Lour.) Baill. & 삼백초(식재) & II \\
2 & Iridaceae & Iris koreana Nakai & 노랑붓꽃 & \\
\hline
\end{tabular}

Table 4. The list of rare plants in Byeonsanbando National Park.

\begin{tabular}{ccccc}
\hline \hline No. & Family name & Scientific name & Korean name & Criteria \\
\hline 1 & Saururaceae & Saururus chinensis (Lour.) Baill. & 삼백초(식재) & EN \\
2 & Cupressaceae & Juniperus chinensis L & 향나무(식재) & VU \\
3 & Iridaceae & Iris koreana Nakai & 노랑붓꽃 \\
4 & Oleaceae & Abeliophyllum distichum Nakai & 미선나무 \\
5 & Hypodematiaceae & Hypodematium glanduloso-pilosum (Tagawa) Ohwi & 금털고사리 & NT \\
\hline
\end{tabular}

EN, endangered; VU, vulnerable; NT, near threatened.

암면 노령 일대에서 최초 발견된 한반도 고유식물로서 (Nakai, 1914), 변산반도 일대와 내장산 일대에 주로 분포 하며 순창 조계산에는 극소수의 개체가 분포하고 있다. 조사지역 내 가장 큰 군락은 도청리(각수암골) 일대로서 수십 개체로 이루어진 소규모 집단이 계곡부를 따라 100 여 곳 이상 확인되었으며, 감교리 일대 구릉지대에서는 숲 가장자리를 중심으로 수백 개체가 확인되었다. 대항리 (어룡골), 중계리(구시골), 운산리(운산제) 인근에는 10 여 개체씩 산발적으로 분포하고 있었다. 이번 조사를 통해 새롭게 확인된 대항리(어룡골) 자생지는 사람의 출입이 갖은 곳에 위치해 있어 훼손이 우려되며, 도청리와 감교 리를 제외한 곳은 개체수가 감소할 가능성이 있어 별도의 관리방안이 필요할 것으로 판단된다. 삼백초는 새만금교 인근의 연못가에 식재되어 있었으며, 제주도의 일부 지역 에만 자생하는 것으로 알려져 있으나 약용으로 전국 곳곳 에서 재배가 이루어지고 있다.

한편, 기존조사에서 확인되었던 멸종위기야생생물 $\mathrm{II}$ 급 대흥란(Cymbidium macrorhizon Lindl.)과 매화마름 (Ranunculus kadzusensis Makino)은 이번 조사에서는 확인 되지 않았다. 이 중 대흥란은 2016년 공원구역 내 리기다 소나무 인공조림지 모니터링 중 분포를 확인하였으나 잎 이 없고 토양의 유기물을 양분으로 살아가는 부생식물의 특성상 이번 조사에서는 확인하지 못하였다. 다만 탐방로 가 없고 인위적 훼손위협이 낮은 지역이므로 지속적으로 개체의 확인 및 개체수 변화 등 모니터링을 수행할 필요 가 있다. 매화마름은 2001년 전국자연환경조사를 통해 최 초 확인되었으나(Sun and Baek, 2001) 자생지가 공원구역 밖에 위치하고 있어 지자체에서 변산해수옥장 관광지 조 성에 따른 매화마름 자생지 파괴를 막기 위해 대체서식지 를 조성하여 2015년 친환경개발 우수사례로 소개되었으 나 불과 1년만인 2016년에 관리미흡에 대한 부정적 언론 보도가 있었다. 본 조사에서 4 월, 6 월, 10 월 3 회에 걸쳐 조
사하였으나 개체를 확인할 수 없었다. 해당 대체서식지는 다른 지역의 매화마름 보호구역과는 달리 숲 가장자리에 위치하고 상층의 교목으로 인하여 그늘져 있으며 매화마 름의 생활사에 가장 중요한 것으로 알려진 경작활동이 전 무하다. 이로 인해 습지 내부에는 큰매자기, 좀개구리밥 등에 의해 완전히 피압되어 있었다. 법적보호종에 대한 대체서식지 조성 시, 해당 종의 생존에 필요한 생리생태 학적 특성, 집단의 크기 등을 면밀히 검토해야 할 것이며 인근 지역을 중심으로 신규 서식지를 발굴하여 종의 보전 을 위한 노력을 지속해야 할 것이다.

\section{희귀식물}

환경부에서 지정한 적색자료집(National Institute of Biological Resources, 2012)에 따른 희귀식물은 총 5 분류군 이 확인되었다(Table 4). 위기종(endangered, EN)에 해당하는 삼백초(식재) 1 분류군, 취약종(vulnerable, $\mathrm{VU}$ )은 노랑붓꽃, 미선나무(Abeliophyllum distichum Nakai), 향나무(Juniperus chinensis L.) (식재) 등 3분류군, 준위협(near threatened, NT) 은 금털고사리[Hypodematium glanduloso-pilosum (Tagawa) Ohwi] 1분류군이 각각 확인되었다(Fig. $3 \mathrm{~A}$, Table 4). VU에 속하는 미선나무는 우리나라 고유속 고유종으로서 지난 2017년 멸종위기식물 II급에서 해제되었다. 알려진 자생지 는 경기도(고양), 충북(괴산, 영동, 진천), 그리고 본 조사지 역인 전북(부안)이다(Lee and Kil, 1991; Kim and Kim, 2008). 본 지역에 위치하는 미선나무 자생지는 남방한계선에 해 당되므로 식물지리학적으로 매우 중요하다고 할 수 있다. 자생지 내 군락은 개화·결실상태가 양호하였으며, 천연기 념물 제 370 호로 지정되어 별도관리가 이루어지고 있으므 로 특별한 위협요인은 없을 것으로 추정되나, 자연적인 군 락의 확대를 기대하기는 어려운 실정이다. 따라서 현재 군 락의 쇠퇴를 대비하여 해당 유전자원을 종자 및 삽목 등의 형태로 확보하여 현지 외 보존이 필요하다고 판단된다. 
Table 5. The list of endemic plants in Byeonsanbando National Park.

\begin{tabular}{cccc}
\hline \hline No. & Family name & Scientific name & Korean name \\
\hline 1 & Amaryllidaceae & Lycoris flavescens M. Kim \& S. T. Lee & 붉노랑상사화 \\
2 & Aristolochiaceae & Asarum maculatum Nakai & 개족도리풀 \\
3 & Caprifoliaceae & Lonicera subsessilis Rehder & 청괴불나무 \\
4 & Caprifoliaceae & Weigela subsessilis (Nakai) L. H. Bailey & 병꽃나무 \\
5 & Cyperaceae & Carex okamotoi Ohwi & 지리대사초 \\
6 & Fabaceae & Indigofera koreana Ohwi & 좀땅비싸리 \\
7 & Fabaceae & Vicia hirticalycina Nakai & 나래완두 \\
8 & Iridaceae & Iris koreana Nakai & 노랑붓꽃 \\
9 & Iridaceae & Iris rossii var. latifolia J. K. Sim \& Y. S. Kim & 넓은잎각시붓꽃 \\
10 & Lamiaceae & Elsholtzia byeonsanensis M. Kim & 변산향유 \\
11 & Liliaceae & Hemerocallis hakuunensis Nakai & 백운산원추리 \\
12 & Moraceae & Broussonetia $\times$ hanjiana M. Kim & 닥나무 \\
13 & Oleaceae & Abeliophyllum distichum Nakai & 미선나무 \\
14 & Oleaceae & Forsythia koreana (Rehder) Nakai & 개나리(식재) \\
15 & Ranunculaceae & Eranthis byunsanensis B. Y. Sun & 변산바람꽃 \\
16 & Ranunculaceae & Thalictrum actaeifolium Siebold \& Zucc. & 은꿩의다리 \\
17 & Salicaceae & Populus $\times$ tomentiglandulosa T. B. Lee & 은사시나무(식재) \\
\hline
\end{tabular}

\section{한반도 고유식물}

한반도 고유식물(Chung et al., 2017)은 개족도리풀(Asarum maculatum Nakai), 변산바람꽃(Eranthis byunsanensis B. Y. Sun), 변산향유(Elsholtzia byeonsanensis M. Kim), 붉노랑상 사화(Lycoris flavescens M. Kim \& S. T. Lee) 등 17분류군이 확인되었다(Table 5). 변산반도에서 최초로 발견되어 신종 으로 발표된 대표적 고유식물로는 변산바람꽃(Sun et al., 1993)과 변산향유(Choi et al., 2012)가 있다. 변산바람꽃 (Fig. 3C)은 청림리(청림마을), 중계리(봉래구곡), 내변산 탐방지원센터-세봉에서 대규모 군락이 확인되었으며, 변 산반도국립공원의 깃대종으로 지정되어 보호되고 있다. 변산향유(Fig. $3 \mathrm{~F}$ )는 최근 한반도 고유종 목록에 포함된 종으로(National Institute of Biological Resources, 2013), 봉 화봉 인근의 바닷가 암벽에서 수십 개체를 확인하였다. 군락 내 개체 수와 생육상태는 양호한 것으로 판단되나 변산반도가 유일한 자생지이기 때문에 적극적인 보전계 획 수립이 필요하다. 개족도리풀은 전북, 전남, 경남, 제주 도 등에 주로 분포하는 남방계식물로서(Flora of Korea Editorial Committee, 2007; Leem and Oh, 2019), 변산반도 내 소사지구, 도청리, 석포리, 중계리 등의 계곡부 주변 및 그 늘진 숲 속에서 흔하게 관찰되었다. 붉노랑상사화는 변산 반도국립공원의 청림리(청림마을), 중계리(봉래구곡)에 서 대규모 군락이 확인되었으며, 본 지역 외에 경기(강화 도), 충남(난지도), 전북(내장산, 모악산, 선운산), 전남(백 양산, 불갑산), 경남(가야산)에도 생육하는 것으로 알려져
있다(Kim, 2004; Kim et al., 2017).

\section{식물구계학적 특정식물종}

식물구계학적 특정식물(Kim et al., 2018)은 총 161분류 군으로 전체 소산식물의 $19.4 \%$ 에 해당하였다(Fig. 3, Table 6). 등급별로는 $\mathrm{V}$ 등급에 노랑붓꽃, 미선나무, 삼백초(식재), 치자풀[Monochasma sheareri (S. Moore) Maxim. ex Franch. \& Sav.), 털오갈피나무[Eleutherococcus divaricatus (Siebold \& Zucc.) S. Y. Hu] 등 5분류군, IV등급에 대반하[Pinellia tripartita (Blume) Schott], 변산향유, 산복사나무[Prunus davidiana (Carrière) Franch.], 산외(Schizopepon bryoniifolius Maxim.) 등 9분류군, III등급에 금난초[Cephalanthera falcata (Thunb.) Blume], 내장고사리[Diplazium squamigerum (Mett.) C. Hope], 새우난초(Calanthe discolor Lindl.), 팥꽃나무 (Daphne genkwa Siebold \& Zucc.) 등 38분류군이 확인되었다. II등급은 34분류군으로 골고사리(Asplenium scolopendrium L.), 나도수정초[Monotropastrum humile (D. Don) H. Hara], 부채괴불이끼[Crepidomanes minutum (Blume) K. Iwats.] 등 이 해당되며, I등급은 75 분류군으로 나도밤나무(Meliosma myriantha Siebold \& Zucc.), 송악[Hedera rhombea (Miq.) Siebold \& Zucc. ex Bean], 좀딱취(Ainsliaea apiculata Sch. Bip.), 큰천남성[Arisaema ringens (Thunb.) Schott], 합다리 나무[Meliosma pinnata (Roxb.) Maxim. var. oldhamii (Miq. ex Maxim.) Beusekom] 등 전반적으로 남방계 식물이 주로 확인되었다. 이번 조사에서 새롭게 확인된 식물구계학적 
Table 6. The list of the $5^{\text {th }}$ to $3^{\text {rd }}$ degree taxa of Korean floristic regional plants in Byeonsanbando National Park.

\begin{tabular}{|c|c|c|c|c|}
\hline No. & Family name & Scientific name & Korean name & Degree \\
\hline 1 & Araliaceae & Eleutherococcus divaricatus (Siebold \& Zucc.) S. Y. Hu & 털오갈피나무 & $\mathrm{V}$ \\
\hline 2 & Iridaceae & Iris koreana Nakai & 노랑붓꽃 & \\
\hline 3 & Oleaceae & Abeliophyllum distichum Nakai & 미선나무 & \\
\hline 4 & Orobanchaceae & Monochasma sheareri (S. Moore) Maxim. ex Franch. \& Sav. & 치자풀 & \\
\hline 5 & Saururaceae & Saururus chinensis (Lour.) Baill. & 삼백초(식재) & \\
\hline 6 & Araceae & Pinellia tripartita (Blume) Schott & 대반하 & IV \\
\hline 7 & Cucurbitaceae & Schizopepon bryoniifolius Maxim. & 산외 & \\
\hline 8 & Cupressaceae & Platycladus orientalis (L.) Franco & 측백나무(식재) & \\
\hline 9 & Fabaceae & Wisteria floribunda (Willd.) DC. & 등(식재) & \\
\hline 10 & Lamiaceae & Elsholtzia byeonsanensis M. Kim & 변산향유 & \\
\hline 11 & Lauraceae & Cinnamomum camphora (L.) J. Presl & 녹나무(식재) & \\
\hline 12 & Oleaceae & Osmanthus heterophyllus (G. Don) P. S. Green & 구골나무(식재) & \\
\hline 13 & Paeoniaceae & Paeonia lactiflora Pall. & 작약(식재) & \\
\hline 14 & Rosaceae & Prunus davidiana (Carrière) Franch. & 산복사나무 & \\
\hline 15 & Aceraceae & Acer palmatum Thunb. & 단풍나무 & III \\
\hline 16 & Aceraceae & Acer triflorum Kom. & 복자기 & \\
\hline 17 & Amaryllidaceae & Lycoris flavescens M. Kim \& S. T. Lee & 붉노랑상사화 & \\
\hline 18 & Aquifoliaceae & Ilex cornuta Lindl. \& Paxton & 호랑가시나무 & \\
\hline 19 & Aquifoliaceae & Ilex crenata Thunb. & 꽝꽝나무 & \\
\hline 20 & Araliaceae & Dendropanax trifidus (Thunb.) Makino ex H. Hara & 황칠나무(식재) & \\
\hline 21 & Aristolochiaceae & Asarum maculatum Nakai & 개족도리풀 & \\
\hline 22 & Athyriaceae & Diplazium squamigerum (Mett.) C. Hope & 내장고사리 & \\
\hline 23 & Convolvulaceae & Calystegia pellita (Ledeb.) G. Don & 선메꽃 & \\
\hline 24 & Crassulaceae & Hylotelephium spectabile (Boreau) H. Ohba & 큰꿩의비름 & \\
\hline 25 & Cupressaceae & Juniperus chinensis $\mathrm{L}$. & 향나무(식재) & \\
\hline 26 & Cyperaceae & Carex genkaiensis Ohwi & 목포사초 & \\
\hline 27 & Flacourtiaceae & Idesia polycarpa Maxim. & 이나무 & \\
\hline 28 & Hydrangeaceae & Philadelphus schrenkii Rupr. & 고광나무 & \\
\hline 29 & Liliaceae & Asparagus cochinchinensis (Lour.) Merr. & 천문동 & \\
\hline 30 & Meliaceae & Melia azedarach $\mathrm{L}$. & 멀구슬나무 & \\
\hline 31 & Orchidaceae & Calanthe discolor Lindl. & 새우난초 & \\
\hline 32 & Orchidaceae & Cephalanthera falcata (Thunb.) Blume & 금난초 & \\
\hline 33 & Pittosporaceae & Pittosporum tobira (Thunb.) W. T. Aiton & 돈나무 & \\
\hline 34 & Poaceae & Lophatherum sinense Rendle & 털조릿대풀 & \\
\hline 35 & Polygonaceae & Polygonum bellardii All. & 큰옥매듭풀 & \\
\hline 36 & Polypodiaceae & Lepisorus onoei (Franch. \& Sav.) Ching & 애기일엽초 & \\
\hline 37 & Pteridaceae & Coniogramme japonica (Thunb.) Diels & 가지고비고사리 & \\
\hline 38 & Ranunculaceae & Actaea asiatica H. Hara & 노루삼 & \\
\hline 39 & Ranunculaceae & Clematis fusca var. violacea Maxim. & 종덩굴 & \\
\hline 40 & Ranunculaceae & Eranthis byunsanensis B. Y. Sun & 변산바람꽃 & \\
\hline
\end{tabular}


Table 6. Continued.

\begin{tabular}{|c|c|c|c|c|}
\hline No. & Family name & Scientific name & Korean name & Degree \\
\hline 41 & Rosaceae & Prunus sargentii Rehder & 산벚나무 & III \\
\hline 42 & Rosaceae & Rubus hirsutus Thunb. & 장딸기 & \\
\hline 43 & Rosaceae & Sanguisorba hakusanensis var. coreana H. Hara & 산오이풀 & \\
\hline 44 & Rosaceae & Spiraea chinensis Maxim. & 당조팝나무 & \\
\hline 45 & Rubiaceae & Mitchella undulata Siebold \& Zucc. & 호자덩굴 & \\
\hline 46 & Rutaceae & Poncirus trifoliatus (L.) Raf. & 탱자나무(식재) & \\
\hline 47 & Sapindaceae & Koelreuteria paniculata Laxm. & 모감주나무(식재) & \\
\hline 48 & Selaginellaceae & Selaginella tamariscina (P. Beauv.) Spring & 바위손 & \\
\hline 49 & Thymelaeaceae & Daphne genkwa Siebold \& Zucc. & 팥꽃나무 & \\
\hline 50 & Urticaceae & Boehmeria pannosa Nakai \& Satake ex Oka & 왕모시풀 & \\
\hline 51 & Verbenaceae & Callicarpa mollis Siebold \& Zucc. & 새비나무 & \\
\hline 52 & Violaceae & Viola violacea Makino & 자주잎제비꽃 & \\
\hline
\end{tabular}

특정식물로는 갯그령[Leymus mollis (Trin.) Pilg.], 금털고사 리, 모새달[Phacelurus latifolius (Steud.) Ohwi], 어리연꽃 [Nymphoides indica (L.) Kuntze], 치자풀, 통보리사초(Carex kobomugi Ohwi), 해국(Aster spathulifolius Maxim.) 등 47분 류군이었다.

이 중 팥꽃나무는 서·남해안(황해도 이남에서부터 전남 진도, 해남, 청산도 등)에 분포하는 남방계식물로 해안가 와 인접한 산기슭이나 술 가장자리의 척박한 곳 또는 관 목림과 어우러진 초지에 산발적으로 흩어져 생육하는 것 으로 알려져 있다(Kim et al., 2018). 본 지역에서는 도청리 수락폭포 인근에서 소수의 개체를 확인하였으나 개체 수 가 적고 관목림과 어우러져 관리가 잘 이루어지고 있지 않으므로, 추가적인 관리 방안이 필요할 것으로 보인다. 골고사리(Fig. 3D)는 '변산일엽'이라고도 불리며(Oh and Lee, 1992), 강원, 전남, 울릉도, 제주도에 분포하는 것으로 알려져 있다(Lee and Lee, 2015). 본 지역에서는 세봉삼거 리 인근 계곡부에서 소수의 개체를 확인하였으며, 본 자 생지에 대한 정밀조사가 이루어진다면 추가적으로 개체 를 확인할 여지는 있으나, 개체수가 적어 향후 쇠퇴할 가 능성이 높아 보인다. 청문에 따르면 과거 비교적 흔하게 분포하였으나 관상용으로 무분별하게 채취되었다고 하 므로 현재 잔존하는 개체에 대한 별도의 보호와 더불어 지속적인 모니터링이 필요한 실정이다. 부채괴불이끼는 한반도 남부, 제주도, 속리산, 설악산, 금강산, 주왕산 등의 그늘지고 습한 바위나 나무에 착생하는 것으로 알려져 있 으며(Korean Fern Society, 2005; Jang et al., 2019), 본 국립공 원지역에서는 내변산탐방지원센터에서 세봉으로 가는 계곡부의 바위 곳곳에서 흔하게 확인할 수 있었다. 새우 난초(Fig. $3 \mathrm{~B}$ )는 갑남산 일대의 낙엽활엽수림에서 10 여 개 체, 운산제의 소나무림에서 70 개체 가량이 확인되었다.
한편, $\mathrm{V}$ 등급에 해당하는 치자풀(Fig. 3E)은 2000년대 이 후 야생화 동호회원들을 통해 변산 일대에서 지속적으로 확인되었다. 조사기간인 2018년도에는 확인하지 못하였 으나 2019년과 2020년에 도청리(각수암골)에 자생하는 것 이 확인되었다. 치자풀은 열당과(Orobanchaceae)에 속하 는 반기생성 식물로서, 최초 한국쌍자엽식물지(Park, 1974)에 기록되었으며, 'Monochasma japonicum (Maxim.) Makino'를 정명으로 취급하고 'Monochasma sheareri var. japonicum Maxim.'을 이명으로 표기하였으나 해당 학명들 은 현재 M. sheareri의 이명으로 처리되고 있다(Yonekura and Kajita, 2003; Tho et al., 2006). 그러나 Tho et al. (2006) 은 본 종을 한국 미기록종으로 오인하여 발표하면서 '변 산붙살이풀'로 신칭함으로서 국명의 혼란을 야기하였다. 본 식물의 현재까지 알려진 자생지는 변산반도를 비롯한 진도, 제주도에 국한되어 있으며, 특정한 환경에서만 출 현하는 식물이므로 본 지역에 대한 지속적인 모니터링과 더불어 별도의 관리대책이 수립되어야 할 것이다.

\section{귀화식물 및 생태계교란식물}

조사지역에서 확인된 귀화식물(Lee et al., 2011)은 총 79 분류군이었으며, 이 중 국화과 식물이 30 분류군(37.9\%)으 로 가장 높은 비율을 차지하였다(Table 7). 귀화율 (naturalization index: 조사된 귀화식물의 종 수[79]/출현식 물의 총 종 수[829]×100) (Numata, 1975)은 9.5\%, 도시화지 수(urbanization index: 조사된 귀화식물의 종 수[79]/남한의 귀화식물 총 종 수[321]×100) (Yim and Jeon, 1980)는 24.6\% 로 산출되어 우리나라 산림형 및 도시형 국립공원의 평균 귀화율과 평균 도시화지수(각각 $6.8 \%, 15.3 \%$ )보다 높게 나타났으나(Yu, 2013), 해안형 국립공원의 평균 귀화율과 평균 도시화지수(각각 $9.6 \%, 25.8 \%$ )와는 유사하였다( $\mathrm{Yu}$, 
Table 7. The list of naturalized plants and ecosystem disturbance plants of Byeonsanbando National Park.

\begin{tabular}{|c|c|c|c|}
\hline No. & Family name & Scientific name & Korean name \\
\hline 1 & Amaranthaceae & Amaranthus blitum subsp. oleraceus (L.) Costea & 개비름 \\
\hline 2 & Amaranthaceae & Amaranthus retroflexus $\mathrm{L}$. & 털비름 \\
\hline 3 & Amaranthaceae & Amaranthus viridis $\mathrm{L}$. & 청비름 \\
\hline 4 & Asteraceae & Ambrosia artemisiifolia $\mathrm{L}$. & 돼지풀a \\
\hline 5 & Asteraceae & Symphyotrichum expansum (Poepp. ex Spreng.) G. L. Nesom & 큰비짜루국화 \\
\hline 6 & Asteraceae & Symphyotrichum pilosum (Willd.) G. L. Nesom & 미국쑥부쟁이 ${ }^{a}$ \\
\hline 7 & Asteraceae & Symphyotrichum subulatum (Michx.) G. L. Nesom & 비짜루국화 \\
\hline 8 & Asteraceae & Bidens frondosa $\mathrm{L}$. & 미국가막사리 \\
\hline 9 & Asteraceae & Bidens pilosa $\mathrm{L}$. & 울산도깨비바늘 \\
\hline 10 & Asteraceae & Carduus crispus $\mathrm{L}$. & 지느러미엉겅퀴 \\
\hline 11 & Asteraceae & Centaurea cyanus $\mathrm{L}$. & 수레국화 \\
\hline 12 & Asteraceae & Conyza canadensis (L.) Cronquist & 망초 \\
\hline 13 & Asteraceae & Erigeron floribundus (Kunth) Sch. Bip. & 큰망초 \\
\hline 14 & Asteraceae & Coreopsis lanceolata $\mathrm{L}$. & 큰금계국 \\
\hline 15 & Asteraceae & Coreopsis tinctoria Nutt. & 기생초 \\
\hline 16 & Asteraceae & Cosmos bipinnatus Cav. & 코스모스 \\
\hline 17 & Asteraceae & Crassocephalum crepidioides (Benth.) S. Moore & 주홍서나물 \\
\hline 18 & Asteraceae & Erechtites hieraciifolius (L.) Raf. ex DC. & 붉은서나물 \\
\hline 19 & Asteraceae & Erigeron annuиs (L.) Pers. & 개망초 \\
\hline 20 & Asteraceae & Erigeron strigosus Muhl. ex Willd. & 주걱개망초 \\
\hline 21 & Asteraceae & Galinsoga ciliata (Raf.) S. F. Blake & 털별꽃아재비 \\
\hline 22 & Asteraceae & Helianthus tuberosus $\mathrm{L}$. & 뚱딴지 \\
\hline 23 & Asteraceae & Hypochaeris radicata $\mathrm{L}$. & 서양금혼초 ${ }^{a}$ \\
\hline 24 & Asteraceae & Lactuca serriola $\mathrm{L}$. & 가시상추a \\
\hline 25 & Asteraceae & Lapsana communis $\mathrm{L}$. & 서양개보리 뺑이 \\
\hline 26 & Asteraceae & Rudbeckia bicolor Nutt. & 원추천인국 \\
\hline 27 & Asteraceae & Senecio vulgaris $\mathrm{L}$. & 개쑥갓 \\
\hline 28 & Asteraceae & Solidago altissima $\mathrm{L}$. & 양미역취a \\
\hline 29 & Asteraceae & Sonchus asper (L.) Hill & 큰방가지똥 \\
\hline 30 & Asteraceae & Tagetes minuta $\mathrm{L}$. & 만수국아재비 \\
\hline 31 & Asteraceae & Taraxacum officinale F. H. Wigg. & 서양민들레 \\
\hline 32 & Asteraceae & Xanthium orientale $\mathrm{L}$. & 큰도꼬마리 \\
\hline 33 & Asteraceae & Xanthium strumarium L. & 도꼬마리 \\
\hline 34 & Brassicaceae & Brassica juncea (L.) Czern. & 갓 \\
\hline 35 & Brassicaceae & Lepidium virginicum $\mathrm{L}$. & 콩다닥냉이 \\
\hline 36 & Cannabaceae & Humulus scandens (Lour.) Merr. & 환삼덩굴ab \\
\hline 37 & Caryophyllaceae & Cerastium glomeratum Thuill. & 유럽점나도나물 \\
\hline 38 & Chenopodiaceae & Atriplex hastata $\mathrm{L}$. & 창명아주 \\
\hline 39 & Chenopodiaceae & Chenopodium album $\mathrm{L}$. & 흰명아주 \\
\hline 40 & Chenopodiaceae & Chenopodium ficifolium $\mathrm{Sm}$. & 좀명아주 \\
\hline
\end{tabular}


Table 7. Continued.

\begin{tabular}{|c|c|c|c|}
\hline No. & Family name & Scientific name & Korean name \\
\hline 41 & Convolvulaceae & Cuscuta pentagona Engelm. & 미국실새삼 \\
\hline 42 & Convolvulaceae & Ipomoea lacunosa $\mathrm{L}$. & 애기나팔꽃 \\
\hline 43 & Convolvulaceae & Ipomoea purpurea (L.) Roth & 둥근잎나팔꽃 \\
\hline 44 & Convolvulaceae & Quamoclit angulata (Lam.) Bojer & 둥근잎유홍초 \\
\hline 45 & Euphorbiaceae & Euphorbia supina Raf. & 애기땅빈대 \\
\hline 46 & Fabaceae & Amorpha fruticosa $\mathrm{L}$. & 족제비싸리 \\
\hline 47 & Fabaceae & Medicago minima (L.) Bartal. & 좀개자리 \\
\hline 48 & Fabaceae & Medicago polymorpha $\mathrm{L}$. & 개자리 \\
\hline 49 & Fabaceae & Medicago sativa $\mathrm{L}$. & 자주개자리 \\
\hline 50 & Fabaceae & Robinia pseudoacacia $\mathrm{L}$. & 아까시나무 \\
\hline 51 & Fabaceae & Trifolium repens $\mathrm{L}$. & 토끼풀 \\
\hline 52 & Fabaceae & Vicia dasycarpa Ten. & 각시갈퀴나물 \\
\hline 53 & Lamiaceae & Lamium purpureum L. & 자주광대나물 \\
\hline 54 & Malvaceae & Abutilon theophrasti Medik. & 어저귀 \\
\hline 55 & Onagraceae & Oenothera biennis $\mathrm{L}$. & 달맞이꽃 \\
\hline 56 & Papaveraceae & Papaver rhoeas L. & 개양귀비 \\
\hline 57 & Phytolaccaceae & Phytolacca americana $\mathrm{L}$. & 미국자리공 \\
\hline 58 & Plantaginaceae & Plantago virginica $\mathrm{L}$. & 미국질경이 \\
\hline 59 & Poaceae & Avena fatua $\mathrm{L}$. & 메귀리 \\
\hline 60 & Poaceae & Bromus catharticus Vahl & 큰이삭풀 \\
\hline 61 & Poaceae & Dactylis glomerata $\mathrm{L}$. & 오리새 \\
\hline 62 & Poaceae & Eragrostis curvula (Schrad.) Nees & 능수참새그령 \\
\hline 63 & Poaceae & Festuca arundinacea Schreb. & 큰김의털 \\
\hline 64 & Poaceae & Vulpia myuros (L.) C. C. Gmel. & 들묵새 \\
\hline 65 & Poaceae & Lolium multiflorum Lam. & 쥐보리 \\
\hline 66 & Poaceae & Panicum dichotomiflorum Michx. & 미국개기장 \\
\hline 67 & Poaceae & Paspalum dilatatum Poir. & 큰참새피 \\
\hline 68 & Polygonaceae & Fallopia dentatoalata (F. Schmidt) Holub & 큰닭의덩굴 \\
\hline 69 & Polygonaceae & Fallopia dumetorum (L.) Holub & 닭의덩굴 \\
\hline 70 & Polygonaceae & Persicaria orientalis (L.) Spach & 털여뀌 \\
\hline 71 & Polygonaceae & Rumex acetosella $\mathrm{L}$. & 애기수영a \\
\hline 72 & Polygonaceae & Rumex crispus $\mathrm{L}$. & 소리쟁이 \\
\hline 73 & Polygonaceae & Rumex obtusifolius L. & 돌소리쟁이 \\
\hline 74 & Saururaceae & Houttuynia cordata Thunb. & 약모밀 \\
\hline 75 & Scrophulariaceae & Lindernia dubia (L.) Pennell & 미국외풀 \\
\hline 76 & Scrophulariaceae & Veronica arvensis L. & 선개불알풀 \\
\hline 77 & Scrophulariaceae & Veronica hederifolia $\mathrm{L}$. & 눈개불알풀 \\
\hline 78 & Scrophulariaceae & Veronica persica Poir. & 큰개불알풀 \\
\hline 79 & Simaroubaceae & Ailanthus altissima (Mill.) Swingle & 가죽나무 \\
\hline 80 & Solanaceae & Solanum americanum Mill. & 미국까마중 \\
\hline
\end{tabular}

${ }^{\mathrm{a}}$ Ecosystem disturbance plant ${ }^{\mathrm{b}}$ Wild plant 


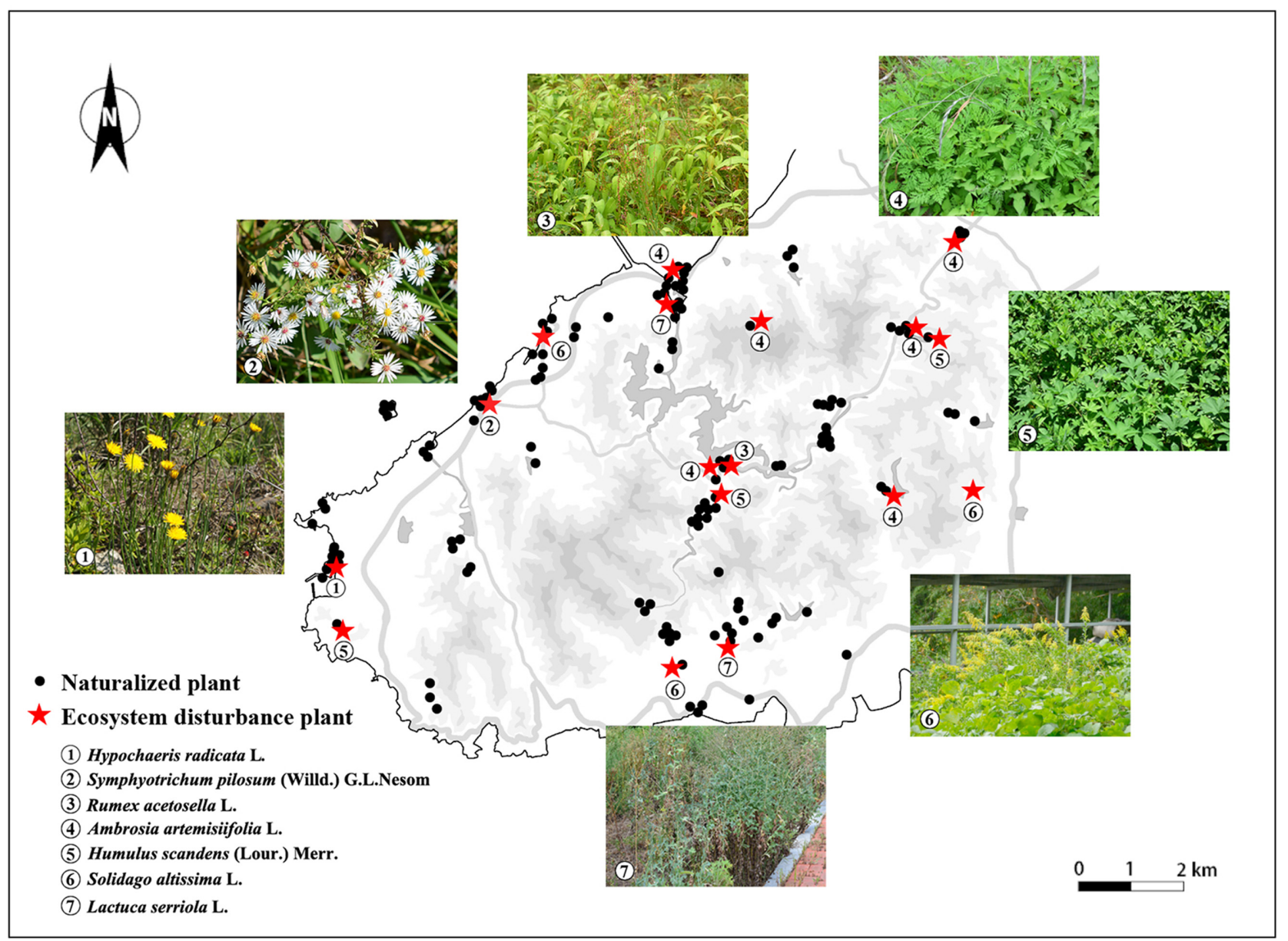

Fig. 4. The distribution map of naturalized plants and ecosystem disturbance plants in Byeonsanbando National Park.

2013). 출현빈도가 높은 곳은 해변로 및 도로 경계부와 주 거지 및 농경지, 임도변, 저지대의 탐방로 주변으로 확인 되었다(Fig. 4).

생태계교란야생식물(Ministry of Environment, 2019)에 해당되는 식물로는 가시상추(Lactuca serriola L.), 돼지풀 (Ambrosia artemisiifolia L.), 미국쑥부쟁이[Symphyotrichum pilosum (Willd.) G. L. Nesom], 서양금혼초(Hypochaeris radicata L.), 양미역취(Solidago altissima L.), 애기수영 (Rumex acetosella L.), 환삼덩굴[Humulus scandens (Lour.) Merr.] 등 7종이 확인되었다(Fig. 4, Table 7). 가시상추는 내 소사 주차장 입구, 변산해수욕장, 새만금교 인근에 비교 적 큰 군락을 이루고 있었고, 돼지풀은 가는골저수지, 청 림제, 내변산로, 새만금교 등 저수지 및 도로변 곳곳에 불 연속적으로 산생하고 있었다. 미국쑥부쟁이는 고사포해 변, 서양금혼초는 채석강(격포리), 애기수영은 내변산로 (중계리)에서 소규모 군락을 확인하였다. 양미역취는 밀 원식물로 도입되어 전라북도 지역에 비교적 넓게 퍼져있 는 생태계교란종으로 공원 구역 곳곳과 인접 지역인 변산 해수욕장 및 보안면 남포리 일대에서 확인되었으며, 특히
보안면(남포리)의 만석동 마을 주변에 큰 군락을 형성하 고 있었다. 따라서 공원 지역을 비롯한 인접 지역의 확산 방지를 위하여 각각의 생육특성 및 생리학적 특성 파악을 통하여 종자산포 이전에 적극적인 방제 조치를 취해야 할 것이다.

\section{유용식물}

산림청의 자원식물 구분에 따르면(Korea Forest Service, 2014), 식용 503분류군, 약용 631분류군, 향료용 30분류군, 산업용 326분류군, 관상용 425 분류군, 생태복원용 330 분 류군, 사료 및 퇴비용 331 분류군으로 각각 파악되었으며, 중복된 항목을 제외하면 전체의 $95 \%$ 에 육박하는 784 분류 군이 이용 가능한 자원식물로 확인되었다. 또한, $54 \%$ 에 해당하는 447 분류군은 예로부터 사용해 왔던 민속식물 (Chung et al., 2013)에 해당되는 것으로 나타났다.

\section{기후변화 취약식물}

기후변화 취약 산림식물(Oh et al., 2010; Oh et al., 2013) 에 해당하는 식물은 39 분류군으로 확인되었으며, 그중 목 
본식물은 35 분류군(89.7\%), 초본식물은 4 분류군(10.3\%) 으로 나타났다(Table 8). 북방계 식물은 복자기(Acer triflorum Kom.), 전나무(Abies holophylla Maxim.) 2분류군 (5.1\%)만이 확인되었으며, 남방계 식물은 개족도리풀, 나

Table 8. The list of the threatened plants for climate change in Byeonsanbando National Park.

\begin{tabular}{|c|c|c|c|c|}
\hline No. & Family name & Scientific name & Korean name & $\mathrm{TP}$ \\
\hline 1 & Aceraceae & Acer palmatum Thunb. & 단풍나무 & $\mathrm{C}$ \\
\hline 2 & Aceraceae & Acer pseudosieboldianum (Pax) Kom. & 당단풍나무 & $\mathrm{C}$ \\
\hline 3 & Aceraceae & Acer triflorum Kom. & 복자기 & $\mathrm{N}$ \\
\hline 4 & Aquifoliaceae & Ilex cornuta Lindl. \& Paxton & 호랑가시나무 & $\mathrm{C}$ \\
\hline 5 & Aquifoliaceae & Ilex crenata Thunb. & 꽝꽝나무 & $\mathrm{S}$ \\
\hline 6 & Araliaceae & Dendropanax morbiferus H. Lév. & 황칠나무(식재) & $\mathrm{S}$ \\
\hline 7 & Aristolochiaceae & Asarum maculatum Nakai & 개족도리풀 & $\mathrm{S}$ \\
\hline 8 & Aspleniaceae & Asplenium scolopendrium $\mathrm{L}$. & 골고사리 & $\mathrm{C}$ \\
\hline 9 & Asteraceae & Dendranthema boreale (Makino) Ling ex Kitam. & 산국 & $\mathrm{C}$ \\
\hline 10 & Betulaceae & Carpinus laxiflora (Siebold \& Zucc.) Blume & 서어나무 & $\mathrm{C}$ \\
\hline 11 & Cornaceae & Cornus officinalis Siebold \& Zucc. & 산수유 & $\mathrm{C}$ \\
\hline 12 & Cupressaceae & Juniperus chinensis L. & 향나무(식재) & $\mathrm{C}$ \\
\hline 13 & Cupressaceae & Thuja orientalis L. & 측백나무(식재) & $\mathrm{C}$ \\
\hline 14 & Ericaceae & Rhododendron mucronulatum Turcz. & 진달래 & $\mathrm{C}$ \\
\hline 15 & Ericaceae & Rhododendron schlippenbachii Maxim. & 철쭉 & $\mathrm{C}$ \\
\hline 16 & Euphorbiaceae & Mallotus japonicus (Thunb.) Müll. Arg. & 예덕나무 & $\mathrm{S}$ \\
\hline 17 & Fabaceae & Albizia julibrissin Durazz. & 자귀나무 & $\mathrm{C}$ \\
\hline 18 & Fabaceae & Robinia pseudoacacia L. & 아까시나무 & $\mathrm{C}$ \\
\hline 19 & Fagaceae & Quercus mongolica Fisch. ex Ledeb. & 신갈나무 & $\mathrm{C}$ \\
\hline 20 & Fagaceae & Quercus serrata Thunb. & 졸참나무 & $\mathrm{C}$ \\
\hline 21 & Ginkgoaceae & Ginkgo biloba $\mathrm{L}$. & 은행나무(식재) & $\mathrm{C}$ \\
\hline 22 & Lauraceae & Cinnamomum camphora (L.) J. Presl & 녹나무(식재) & $\mathrm{C}$ \\
\hline 23 & Lauraceae & Lindera obtusiloba Blume & 생강나무 & $\mathrm{C}$ \\
\hline 24 & Lauraceae & Machilus thunbergii Siebold \& Zucc. & 후박나무 & $\mathrm{C}$ \\
\hline 25 & Magnoliaceae & Magnolia denudata Desr. & 백목련(식재) & $\mathrm{C}$ \\
\hline 26 & Malvaceae & Hibiscus syriacus L. & 무궁화(식재) & $\mathrm{C}$ \\
\hline 27 & Oleaceae & Abeliophyllum distichum Nakai & 미선나무 & $\mathrm{S}$ \\
\hline 28 & Oleaceae & Forsythia koreana (Rehder) Nakai & 개나리(식재) & $\mathrm{C}$ \\
\hline 29 & Oleaceae & Osmanthus heterophyllus (G. Don) P. S. Green & 구골나무(식재) & $\mathrm{S}$ \\
\hline 30 & Pinaceae & Abies holophylla Maxim. & 전나무 & $\mathrm{N}$ \\
\hline 31 & Pinaceae & Pinus densiflora Siebold \& Zucc. & 소나무 & $\mathrm{C}$ \\
\hline 32 & Pittosporaceae & Pittosporum tobira (Thunb.) W. T. Aiton & 돈나무 & S \\
\hline 33 & Ranunculaceae & Eranthis byunsanensis B. Y. Sun & 변산바람꽃 & $\mathrm{S}$ \\
\hline 34 & Rosaceae & Prunus sargentii Rehder & 산벚나무 & $\mathrm{C}$ \\
\hline 35 & Sabiaceae & Meliosma myriantha Siebold \& Zucc. & 나도밤나무 & $\mathrm{S}$ \\
\hline 36 & Salicaceae & Salix gracilistyla Miq. & 갯버들 & $\mathrm{C}$ \\
\hline 37 & Sapindaceae & Koelreuteria paniculata Laxmann & 모감주나무(식재) & $\mathrm{C}$ \\
\hline 38 & Theaceae & Camellia japonica $\mathrm{L}$. & 동백나무(식재) & $\mathrm{C}$ \\
\hline 39 & Verbenaceae & Callicarpa mollis Siebold \& Zucc. & 새비나무 & $\mathrm{S}$ \\
\hline
\end{tabular}

$\mathrm{TP}$, threatened plants for climate change (C, concern; $\mathrm{N}$, northern race; $\mathrm{S}$, southern race) 
도밤나무, 돈나무[Pittosporum tobira (Thunb.) W. T. Aiton], 변산바람꽃, 새비나무(Callicarpa mollis Siebold \& Zucc.), 예덕나무[Mallotus japonicus (L. f.) Müll.Arg.] 등 10분류군 (25.6\%)이 확인되었다. 이 중 예덕나무, 나도밤나무와 새비 나무는 조사구역 내 산림지역에서 흔하게 출현하였다. 관 심식물로는 골고사리, 당단풍나무[Acer pseudosieboldianum (Pax) Kom.], 자귀나무(Albizia julibrissin Durazz.), 진달래 (Rhododendron mucronulatum Turcz.), 철쭉(Rhododendron schlippenbachii Maxim.), 호랑가시나무(Ilex cornuta Lindl. \& Paxton), 후박나무(Machilus thunbergii Siebold \& Zucc.) 등 27분류군(69.2\%)으로 나타났으며, 골고사리를 제외한 나머지 종들은 조사지역 내에서 매우 흔하게 관찰되었다. 도청리의 호랑가시나무군락과 격포리의 후박나무군락은 천연기념물 제 122 호와 제 123 호로 지정하여 보호하고 있다.

\section{선행연구와의 비교}

본 조사결과와 변산반도국립공원의 선행연구(Jeom, 1990; Sun et al., 1995; Oh, 1999; Sun and Baek, 2001; Im and Hong, 2006; Oh and Beon, 2009; Oh et al., 2013) 결과를 취합하여 비교·검토하였다. 취합된 목록을 국가표준식물 목록(Korea National Arboretum, 2017)과 국가생물종목록 (National Institute of Biological Resources, 2019) 등에 준하 여 정리한 결과 총 148 과 571 속 1,127 종 5 아종 129 변종 20 품종의 총 1,281 분류군으로 집계되었다. 기존의 식물목록 에 기록되지 않은 식물은 67 과 151 속 168 종 3 아종 14 변종 1 품종의 186 분류군으로 확인되었으며, 이번 조사에서 새 로이 확인된 분류군은 관속식물목록(Appendix 1)의 일련 번호 앞에 ^로 표시하였다. 이 중 이번 조사에서 처음으 로 확인된 적색자료집 식물에는 금털고사리, 나도수정초, 모새달, 새박, 새우난초 등이 관찰되었고, 고유식물로는 나래완두(Vicia hirticalycina Nakai), 넓은잎각시붓꽃(Iris rossii Baker var. latifolia J. K. Sim \& Y. S. Kim), 변산향유 등이 분포하는 것을 확인하였다. 그 외에도 식물구계학적 특정식물인 갯까치수염(Lysimachia mauritiana Lam.), 노랑 어리연꽃 [Nymphoides peltata (S. G. Gmel.) Kuntze], 부채괴 불이끼, 선메꽃[Calystegia dahurica (Herb.) Choisy], 세뿔석 위[Pyrrosia hastata (Houtt.) Ching], 어리연꽃, 애기일엽초 [Lepisorus onoei (Franch. \& Sav.) Ching], 옥녀꽃대 [Chloranthus fortunei (A. Gray) Solms], 치자풀, 큰옥매듭풀 (Polygonum bellardii All.) 등 47분류군이 새로 발견되었다.

이번 조사에서 기존문헌에 기록되어있지만 확인하지 못 한 식물은 92과 279속 385종 1아종 40변종 13품종의 439분 류군으로 집계되었다. 이 중 멸종위기식물인 매화마름과 끈끈이귀개(Drosera peltata Thunb. var. nipponica (Masam.) Ohwi ex E. Walker)의 경우, 매화마름 자생지는 대항리 바닷 가 인근의 논둑에서 발견(Sun and Baek, 2001)되었으나 현재 도로 개발로 훼손된 상태이며, 변산해수욕장에 조성된 대 체서식지에서도 식물체를 확인할 수 없었다. 수중 종자산
포와 더불어 끊어진 줄기의 마디로 번식하는 매화마름의 생존전략으로 미루어 볼 때 주변 논 경작지를 상세히 조사 한다면 추가적인 자생지를 발견할 가능성도 있을 것으로 판단된다. 끈끈이귀개도 기존의 자생지(Sun and Baek, 2001)에서는 확인할 수 없었으며, 생육지 환경의 변화와 주 변의 개발로 인해 절멸된 것으로 판단된다. 그 외에도 환경 부 적색자료집 식물 중 위기종 $(\mathrm{EN})$ 에 해당하는 승마 [Actaea heracleifolia (Kom.) J. Compton], 취약종(VU)에 해당 하는 산개나리[Forsythia saxatilis (Nakai) Nakai], 솔잎가래 (Potamogeton pectinatus L.), 꼬마은난초(Cephalanthera subaphylla Miyabe \& Kudô), 애기사철란[Goodyera repens (L.) R. Br.], 관심대상종(LC)에 해당하는 수정난풀(Monotropa uniflora L.), 개쓴풀[Swertia diluta var. tosaensis (Makino) H. Hara], 말나리(Lilium distichum Nakai ex Kamib.), 왕둥굴레 [Polygonatum robustum (Korsh.) Nakai], 흰제비란(Platanthera hologlottis Maxim.), NT에 해당하는 백작약[Paeonia japonica (Makino) Miyabe \& Takeda], 채고추나물(Hypericum attenuatum Fisch. ex Choisy), 흑삼릉[Sparganium stoloniferum (Graebn.) Buch.-Ham. ex Juz.], 큰방울새란(Pogonia japonica Rchb. f.) 등이 기존 문헌 목록에 기록되어 있으나, 이번 조 사에서는 확인하지 못하였다. 이 중 왕둥굴레의 경우 울릉 도의 제한된 지역에서 기록이 확인된 종으로서 재확인이 필요할 것으로 판단된다(Jang, 2002). 실제 분포가 의심스러 운 종으로는 강원도 이북, 태백산, 주왕산 등으로 기록되어 있는 노랑갈퀴(Vicia chosenensis Ohwi), 경기 및 강원 북부지 역에 자생하는 산토끼고사리[Gymnocarpium jessoense (Koidz.) Koidz.], 북방계식물인 이삭바꽃(Aconitum kusnezoffii Rchb.), 갈매나무(Rhamnus davurica Pall.), 매자나 무(Berberis koreana Palib.) 등이 이에 해당한다(Flora of Korea Editorial Committee 2007; Oh et al., 2016).

ORCID: Hyosun LEEM https://orcid.org/0000-0002-91032512; Seahee HAN https://orcid.org/0000-0002-8310-6171; Hyun-Do JANG https://orcid.org/0000-0001-7556-3682; Yoon-Young KIM https://orcid.org/0000-0003-4954-6365; Soonku SO https://orcid.org/0000-0001-7044-5441

\section{Acknowledgments}

The authors deeply thank to Mr. N. Y. Kim for providing the information and photographs of plants. This work was supported by a grant from 'Natural resource survey in Byeonsanbando National Park in 2018' of Korea National Park Research Institute (no NPRI 2018-43).

\section{Conflict of Interest}

The authors declare that there are no conflics of interest. 


\section{Literature Cited}

Cho, Y. H., J. H. Kim and S. H. Park. 2016. Grasses and Sedges in South Korea. Geobook, Seoul, 527 pp. (in Korean)

Choi, C., K. Han, J. Lee, S. So, Y. Hwang and M. Kim. 2012. A new species of Elsholtzia (Lamiaceae): E. byeonsanensis M. Kim. Korean Journal of Plant Taxonomy 42: 197-201. (in Korean)

Christenhusz, M. J. M., X.-C. Zhang and H. Schneider. 2011. A linear sequence of extant families and genera of lycophytes and ferns. Phytotaxa 19: 7-54.

Chung, G. Y., K. S. Chang, J.-M. Chung, H. J. Choi, W.-K. Paik and J.-O. Hyun. 2017. A checklist of endemic plants on the Korean Peninsula. Korean Journal of Plant Taxonomy 47: 264-288. (in Korean)

Chung, J. M., G. W. Park, H. R. Jeong, S. K. So, H. J. Kim, K. Choi, C. H. Lee, C. H. Shin and S. S. Kim. 2013. Ethnobotany in Korea: The Traditional Knowledge and Use of Indigenous Plants. Korea National Arboretum, Pocheon, 1276 pp. (in Korean)

Cultural Heritage Administration. 2000. Cultural heritage search. Retrieved Dec. 5, 2019, available from http://www.cha.go.kr.

Flora of Korea Editorial Committee. 2007. The Genera of Vascular Plants of Korea. Academy Publishing Co., Seoul, 1482 pp. (in Korean)

Im, H.-T. and H. H. Hong. 2006. The 3rd National Natural Environment Survey. Flora of Mapo Vicinage: Ssangseonbong. National Institute of Environmental Research, Incheon, 12 pp. (in Korean)

Jang, C.-G. 2002. A taxonomic review of Korean Polygonatum (Ruscaceae). Korean Journal of Plant Taxonomy 32: 417-447. (in Korean)

Jang, H.-D., H. Leem, S. Han and S. So. 2019. Floristic study of Juwangsan National Park in Korea. Korean Journal of Plant Resources 32: 379-406. (in Korean)

Jeom, H. Y. 1990. Flora of Pyonsan Peninsula in Buan. MS thesis, Wonkwang University, Iksan, Korea, 43 pp. (in Korean)

Kim, C. H., M. O. Moon, J. K. Ahn, I. C. Hwang, S. H. Lee, S. S. Choi, J. H. Lee, H. M. Bum, C. G. Kim and J. Y. Cha. 2018. Floristics Target Species in Korea. National Institute of Ecology, Seocheon, 728 pp. (in Korean)

Kim, D.-K. and J.-H. Kim. 2008. A new natural habitat of Abeliophyllum distichum Nakai. Korean Journal of Plant Taxonomy 38: 573-582. (in Korean)

Kim, J. S. and T. Y. Kim. 2011. Woody Plants of Korea Peninsula. Dolbegae, Paju, 688 pp. (in Korean)

Kim, M. 2004. A taxonomic review of Korean Lycoris (Amaryllidaceae). Korean Journal of Plant Taxonomy 34: 9-26. (in Korean)
Kim, Y.-Y., H. Leem, S. Han, S.-J. Ji and S. So. 2017. Conservation measures and distribution of vulnerable species for climate change in Gayasan National Park. Korean Journal of Plant Resources 30: 167-175. (in Korean)

Korea Forest Service. 2014. The Assessment for Vascular Plant Resources and the Reclassification of Their Usefulness from Korea. Korea Forest Service, Daejeon, Pp. 10-153. (in Korean)

Korea Meteorological Administration. 2019. Climate statistical analysis. Retrieved Dec. 5, 2019, available from http:// www.kma.go.kr.

Korea National Arboretum. 2017. Checklist of Vascular Plants in Korea. Korea National Arboretum, Pocheon, 1,000 pp. (in Korean)

Korean Fern Society. 2005. Ferns and Fern Allies of Korea. Geobook, Seoul, 399 pp. (in Korean)

Lee, C. S. and K. H. Lee. 2015. Pteridophytes of Korea: Lycophytes and Ferns. Geobook, Seoul, 471 pp. (in Korean)

Lee, T. B. 2003. Coloured Flora of Korea, Vol. I, II. Hyangmunsa, Seoul, Vol. I, 914 pp, Vol. II, 910 pp. (in Korean)

Lee, W. T. 1996. Coloured Standard Illustrations of Korean Plants. Academy Publishing Co., Seoul, 624 pp. (in Korean)

Lee, W. T. and B. S. Kil. 1991. The investigation on natural growth region of Abeliophyllum distichum Nakai. Korean Journal of Plant Taxonomy 21: 1-8. (in Korean)

Lee, W. T. and Y. J. Yim. 2002. Plant Geography with Special Reference to Korea. Kangwon National University Press, Chuncheon, 412 pp. (in Korean)

Lee, Y.-M., S.-H. Park, S.-Y. Jung, S.-H. Oh and J.-C. Yang. 2011. Study on the current status of naturalized plants in South Korea. Korean Journal of Plant Taxonomy 41: 87-101. (in Korean)

Leem, H. and B.-U. Oh. 2019. Taxonomy of Korean Asarum (Aristolochiaceae) by the morphological characters. Korean Journal of Plant Resources 32: 344-354. (in Korean)

Lim, K. B. and K. J. Lee. 1999. An Introduction to Forestry. Hyangmunsa, Seoul, 393 pp. (in Korean)

Ministry of Environment. 2017. Wildlife protection and management. Retrieved Dec. 5, 2019, available from http:// www.me.go.kr.

Ministry of Environment. 2019. Appoint notice of ecosystem disturbance wild plant. Retrieved Dec. 9, 2019, available from http:// www.kbr.go.kr.

National Institute of Biological Resources. 2012. Red Data Book of Endangered Vascular Plants in Korea. National Institute of Biological Resources, Incheon, 391 pp. (in Korean)

National Institute of Biological Resources. 2013. Endemic Species of Korea. National Institute of Biological Resources, Incheon, 912 pp. (in Korean)

National Institute of Biological Resources. 2019. National list of 
species of Korea. Retrieved Dec. 5, 2019, available from http:// www.kbr.go.kr.

Nakai, T. 1914. Plantae novae Coreanae et Japonicae I. The Botanical Magazine Tokyo 28: 517-520. (in Japanese)

Numata, M. 1975. Naturalized Plants. Dai Nippon Printing Co., Tokyo, 160 pp. (in Japanese)

Oh, B.-U., D. G. Jo, S. C. Ko, B. H. Choi, W.-K. Park, G. Y. Chung, Y. M. Lee and C.-G. Jang. 2010. 300 Target Plants Adaptable to Climate Change in the Korean Peninsula. Korea Forest Service and Korea National Arboretum, Pocheon, 492 pp. (in Korean)

Oh, B.-U., S. C. Ko, S. H. Kang, W.-K. Baik, K. O. Yoo, H.-T. Im, C.-G. Jang, G. Y. Chung, B. H. Choi, H. J. Choi, Y. M. Lee, C. H. Shin, K. Choi, J. H. Han, S. H. Park, H. J. Kim, G. S. Chang, J. C. Yang, S. Y. Jeong, C. H. Lee, S. H. Oh and D. G. Jo. 2016. Distribution Maps of Vascular Plants in Korea. Korea Forest Service and Korea National Arboretum, Pocheon, 809 pp. (in Korean)

Oh, H.-K. 2017. Vascular plants distributed in the Iris koreana of Gaeamsa temple and Soeppulbawi rock areas in special protection zones of Byeonsanbando National Park. Journal of Environmental Impact Assessment 26: 365-375. (in Korean)

Oh, H.-K. and M.-S. Beon. 2009. Analysis on community and flora of Jakeundang in the Byeonsanbando National Park. Korean Journal of Environment and Ecology 23: 177-186. (in Korean)

Oh, H.-K., Y.-H. Han, J.-H. Lee and M.-S. Soh. 2011a. The flora of Haseom Island, Byeonsanbando National Park. Journal of National Park Research 2: 165-172. (in Korean)

Oh, H. K., Y. H. Han and K. U. Park. 2011b. Vegetation present and vascular plants of habitats Lycoris flavescens M. Y. Kim et S. T. Lee and Iris koreana Nakai, Byeonsanbando. Journal of Agriculture and Life Sciences 42: 54-67. (in Korean)

Oh, H. K., Y. H. Han and K. W. Park. 2013. Resource Monitering of Byeonsanbando National Park: Habitat Survey of the Specific Plants. Korea National Park Service, Byeonsanbando National Park Office, Buan, 388 pp. (in Korean)

Oh, H.-K., S.-K. Park and J.-Y. Yang. 2008. The flora of the Sojeokgol in Byunsan Peninsula. Journal of the Korean Society of Plant and Environmental Design 4: 29-36. (in Korean)

Oh, J. G. 1999. Natural Resource Survey in Byeonsanbando National Park: Flora. Korea National Park Research Institute, Namwon. Pp. 26-63. (in Korean)

Oh, S. H., Y. M. Lee, J. C. Yang, J. W. Jang, J. G. Byeon, J. E. Yun, B. D. Kim, C. H. Bae, J. S. Sim, C. H. Lee, G. Y. Lee, J. M. Park, C. J. Oh, J. S. Sin and D. S. Kim. 2013. Manual of Conservation Project of Threatened Plants for Climate Change. Korea National Arboretum, Pocheon, 243 pp. (in Korean)

Oh, Y. C. and C. S. Lee. 1992. Flora of Korean Pteridophyta II.
Sungshin Women's University Research Collection of Dissertations 32: 271-301. (in Korean)

Park, M. K. 1974. Keys to the Herbaceous Plants in Korea (Dicotyledoneae). Jeongeumsa, Seoul. P. 406. (in Korean)

Park, S. H. 2009. New Illustrations and Photographs of Naturalized Plants of Korea. Ilchokak, Seoul, 575 pp. (in Korean)

Park, S. H., Y. M. Lee, S. Y. Jung, K. S. Chang, W. C. Kang, S. S. Jung, S. H. Oh and J. C. Yang. 2011. Illustrated Grasses of Korea (Revised and Enlarged Edition). Korean National Arboretum, Pocheon, 600 pp. (in Korean)

Park, S. H., Y. M. Lee, J. C. Yang, D. G. Jo, G. H. Lee, C. S. Jang, H. J. Lee, H. J. Choi, S. S. Jung and J. H. Lee. 2008. Illustrated Pteridophytes of Korea. Korea National Arboretum, Pocheon, 547 pp. (in Korean)

So, S., H.-H. Myeong, E.-K. Kim, S. H. Kang, J.-H. Lee and J.-G. Oh. 2016. Status on the Korean Red List of Threatened Species in Korea National Park. Journal of National Park Research 7: 90-103. (in Korean)

Sun, B. Y. and T. G. Baek. 2001. The 2nd National Natural Environment Survey: Flora of Mt. Uisangbong (Buan) and Its Vicinage. National Institute of Environmental Research, Incheon. Pp. 86-127. (in Korean)

Sun, B. Y., C. H. Kim and T. J. Kim. 1993. A new species of Eranthis (Ranunculaceae) from Korea: E. byunsanensis. Korean Journal of Plant Taxonomy 23: 21-26. (in Korean)

Sun, B. Y., C. H. Kim and J. S. Suh. 1995. Flora of Pyonsan Peninsula National Park. Bulletin of the Korean Association for Conservation of Nature 34: 19-48. (in Korean)

Tho, J.-H., K.-H. Tae, J. Lee and J. H. Kim. 2006. An unrecorded species in Korea: Monochasma sheareri (S. Moore) maxim, ex Franch. Et Sav. (Scrophulariaceae). Journal of Plant Biology 49: 336-338.

Yang, H. S., J. H. Jung and J. S. Kim. 2009. Natural Resource Survey in Byeonsanbando National Park: Flora. Korea National Park Research Institute, Namwon. Pp. 71-110. (in Korean)

Yim, Y. J. and E. S. Jeon. 1980. Distribution of naturalized plants in the Korean peninsula. Korean Journal of Botany 23: 69-83. (in Korean)

Yu, J. 2013. Cultural exclusion and negative perception related to naturalized plants derived from academic discussion. Journal of the Korea Society of Environmental Restoration Technology 16: 63-74. (in Korean)

Yuk, K. S. and D. M. Park. 2019. Natural Resource Survey in Byeonsanbando National Park: The General Status. Korea National Park Research Institute, Wonju. Pp. 11-17. (in Korean)

Yonekura, K. and T. Kajita. 2003. Y List. Retrieved Apr. 25, 2020, available from http://ylist.info. 


\section{변산반도국립공원의 관속식물상}

\section{임효선 · 한세희 ${ }^{1} \cdot$ 장현도 ${ }^{2} \cdot$ 김윤영 ${ }^{3} \cdot$ 소순구 ${ }^{4 *}$}

국립백두대간수목원 산림복원지원실, ${ }^{1}$ 국립농업과학원 농업유전자원센터, ${ }^{2}$ 국립생물자원관 식물자원과,

${ }^{3}$ 국립산림품종관리센터 품종심사과, ${ }^{4}$ 국립공원공단 국립공원연구원

적 요: 변산반도국립공원을 대상으로 2018년도 3월부터 10 월까지 총 33일에 걸쳐 조사를 수행하였다. 증거 표본과 사진을 바탕으로 작성한 관속식물은 141과 458속 748종 16아종 59변종 6품종의 총 829분류군으로 기록되었다. 이 중 멸종위기식물은 노랑붓꽃, 삼백초(식재) 등 2 분류군이 확인되었고, 희귀식물은 미선나무, 금털고사리 등 5 분류군이 관찰되었다. 한반도 고유식물은 붉노랑상사화, 변산향유, 변산바람꽃 등 17 분류군 이 조사되었고, 식물구계학적 특정식물종은 III-V등급에 해당하는 52분류군이 확인되었다. 귀화식물은 총 79 분류군으로 생태계교란종은 돼지풀, 가시상추, 양미역취 등 7 분류군이 확인되었다. 기후변화 취약종은 총 39 분류군이 분포하였고, 북방계 2 분류군, 남방계 10 분류군, 관심식물은 27 분류군으로 확인되었다. 기존 조사에 서는 확인되지 않았으나, 본 조사를 통해 새롭게 밝혀진 분류군은 186 분류군이었다.

주요어: 변산반도국립공원, 식물상, 멸종위기 및 희귀식물, 특산식물, 귀화식물 
Appendix 1. The list of vascular plants of Byeonsanbando National Park including voucher specimens ( $\star$ : newly recorded plant in this study, *: planted or cultivated plant)

\section{LYCOPODIACEAE 석송과}

1. Huperzia serrata (Thunb.) Trevis. 뱀톱 BS 20180014

2. Lycopodium clavatum L. 석송 BS_20180698

SELAGINELLACEAE 부처손과

3. Selaginella tamariscina (P. Beauv.) Spring 바위손 BS 20180585 EQUISETACEAE 속새과

4. Equisetum arvense L. 쇠뜨기 BS 20180720

OPHIOGLOSSACEAE 고사리삼과

5. Botrychium ternatum (Thunb.) Sw. 고사리삼 BS 20180387

OSMUNDACEAE 고비과

6. Osmunda japonica Thunb. 고비 BS_20180385

HYMENOPHYLLACEAE 처녀이끼과

$\star 7$. Crepidomanes minutum (Blume) K. Iwats. 부채괴불이끼 BS 20180005

DENNSTAEDTIACEAE 잔고사리과

8. Pteridium aquilinum (L.) Kuhn var. latiusculum (Desv.) Underw. ex

A. Heller 고사리 BS 20180386

PTERIDACEAE 봉의꼬리과

9. Coniogramme japonica (Thunb.) Diels 가지고비고사리 BS 20180010

\section{ASPLENIACEAE 꼬리고사리과}

10. Asplenium incisum Thunb. 꼬리고사리 BS 20180424

11. Asplenium scolopendrium L. 골고사리 BS_20180145

$\star$ 12. Asplenium varians Wall. ex Hook. \& Grev. 애기꼬리고사리 BS 20180753

\section{THELYPTERIDACEAE 처녀고사리과}

13. Parathelypteris glanduligera (Kunze) Ching 사다리고사리 BS_20180646

14. Parathelypteris japonica (Baker) Ching 지네고사리 BS 20180872 ATHYRIACEAE 개고사리과

15. Athyrium niponicum (Mett.) Hance 개고사리 BS_20180342

16. Diplazium squamigerum (Mett.) C. Hope 내장고사리 BS_20180448 HYPODEMATIACEAE 금털고사리과

$\star$ 17. Hypodematium glanduloso-pilosum (Tagawa) Ohwi 금털고사리 BS 20180414

\section{DRYOPTERIDACEAE 관중과}

18. Cyrtomium falcatum (L.f.) C. Presl 도깨비쇠고비 BS 20180485

19. Cyrtomium fortunei J.Sm. 쇠고비 BS_20180141

20. Dryopteris chinensis (Baker) Koidz. 가는잎족제비고사리 BS_20180325

21. Dryopteris lacera (Thunb.) Kuntze 비늘고사리 BS 20180139

22. Dryopteris setosa (Thunb.) Akasawa 산족제비고사리

BS_20180673

$\star$ 23. Dryopteris uniformis (Makino) Makino 곰비늘고사리 BS_20180395

24. Polystichum tripteron (Kunze) C. Presl 십자고사리 BS_20180143 DAVALLIACEAE 넉줄고사리과

25. Davallia mariesii T. Moore ex Baker 넉줄고사리 BS 20180296 POLYPODIACEAE 고란초과

$\star 26$. Lepisorus onoei (Franch. \& Sav.) Ching 애기일엽초 BS 20180764

$\star 27$. Lepisorus ussuriensis (Regel \& Maack) Ching 산일엽초 BS_20180272

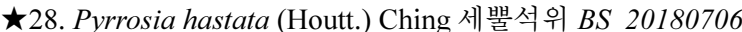

$\star 29$. Pyrrosia linearifolia (Hook.) Ching 우단일엽 BS_20180801 GINKGOACEAE 은행나무과

30. Ginkgo biloba L. 은행나무*BS_20180811

PINACEAE 소나무과
Appendix 1. Continued.

31. Abies holophylla Maxim. 전나무 BS 20180831

32. Cedrus deodara (Roxb. ex D. Don) G. Don 개잎갈나무* BS_20180362

33. Pinus densiflora Siebold \& Zucc. 소나무 BS 20180048

34. Pinus thunbergii Parl. 곰솔 BS_20180396

CUPRESSACEAE 측백나무과

35. Chamaecyparis obtusa (Siebold \& Zucc.) Endl. 편백* BS 20180959 36. Cryptomeria japonica (Thunb. ex L.f.) D. Don 삼나무* BS_20180678

$\star 37$. Juniperus chinensis L. 향나무* BS_20180971

38. Juniperus rigida Siebold \& Zucc. 노간주나무 BS_20180452

39. Metasequoia glyptostroboides Hu \& W. C. Cheng 메타세쿼이아* BS 20180543

40. Platycladus orientalis (L.) Franco 측백나무* BS 20180905

$\star 41$. Thuja occidentalis L. 서양측백* BS_20180696

JUGLANDACEAE 가래나무과

42. Juglans regia L. 호두나무* BS 20180975

43. Platycarya strobilacea Siebold \& Zucc. 굴피나무 BS_20180097

SALICACEAE 버드나무과

44. Populus alba L. 은백양* BS_20180809

45. Populus deltoides Marsh. 미류나무* BS 20180578

$\star$ 46. Populus nigra L. 양버들* BS_20180771

47. Populus $\times$ tomentiglandulosa T.B.Lee 은사시나무*BS_20180810

48. Salix babylonica L. 수양버들* BS 20180735

49. Salix gracilistyla Miq. 갯버들 BS_20180370

50. Salix pierotii Miq. 버드나무 BS 20180605

$\star$ 51. Salix pseudolasiogyne H. Lév. 능수버들* BS_20180464

BETULACEAE 자작나무과

52. Alnus firma Siebold \& Zucc. 사방오리* BS 20180208

53. Alnus incana (L.) Moench subsp. hirsuta (Turcz. ex Spach) Á. Löve

\& D. Löve 물오리나무 BS 20180564

54. Carpinus cordata Blume 까치박달 BS 20180422

55. Carpinus laxiflora (Siebold \& Zucc.) Blume 서어나무 BS 20180697

56. Carpinus turczaninowii Hance 소사나무 BS_20180055

57. Corylus heterophylla Fisch. ex Trautv. 난티잎개암나무 BS_20180445

58. Corylus sieboldiana Blume var. mandshurica (Maxim.) C. K.

Schneid. 물개암나무 BS 20180556

FAGACEAE 참나무과

59. Castanea crenata Siebold \& Zucc. 밤나무* BS 20180592

$\star 60$. Castanea mollissima Blume 약밤나무* BS_20180769

61. Quercus acutissima Carruth. 상수리나무 BS_20180684

62. Quercus aliena Blume 갈참나무 $B S 20180201$

63. Quercus dentata Thunb. 떡갈나무 BS 20180518

64. Quercus mongolica Fisch. ex Ledeb. 신갈나무 BS 20180740

65. Quercus serrata Murray 졸참나무 BS_20180171

66. Quercus variabilis Blume 굴참나무 BS_20180178

ULMACEAE 느릅나무과

67. Celtis biondii Pamp. 폭나무 BS_20180960

68. Celtis sinensis Pers. 팽나무 BS 20180304

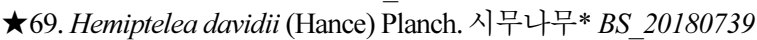

70. Zelkova serrata (Thunb.) Makino 느티나무 BS 20180463

EUCOMMIACEAE 두충과

71. Eucommia ulmoides Oliv. 두충* BS_20180501

MORACEAE 뽕나무과

72. Broussonetia kazinoki Siebold ex Siebold \& Zucc. 애기닥나무 BS 20180756

73. Broussonetia papyrifera (L.) L'Hér. ex Vent. 꾸지나무 BS 20180431 
Appendix 1. Continued.

74. Broussonetia $\times$ hanjiana M. Kim 닥나무 BS_20180105

75. Cudrania tricuspidata (Carrière) Bureau ex Lavallée 꾸지뽕나무 BS_20180432

76. Fatoua villosa (Thunb.) Nakai 뽕모시풀 BS 20180645

77. Ficus carica L. 무화과나무* BS 20180555

78. Morus alba L. 뽕나무* BS_20180644

79. Morus australis Poir. 산뽕나무 BS_20180665

CANNABACEAE 삼과

80. Humulus scandens (Lour.) Merr. 환삼덩굴 BS 20180978

\section{URTICACEAE 쐐기풀과}

$\star 81$. Achudemia japonica Maxim. 산물통이 BS_20180660

82. Boehmeria japonica (L. f.) Miq. 왜모시풀 $B S 20180798$

83. Boehmeria nivea (L.) Gaudich. 모시풀* BS_20180551

84. Boehmeria pannosa Nakai \& Satake ex Oka 왕모시풀 BS 20180793

85. Boehmeria platanifolia (Franch. \& Sav.) C.H.Wright 개모시풀 BS 20180350

86. Boehmeria spicata (Thunb.) Thunb. 좀깨잎나무 BS_20180848 SANTALACEAE 단향과

87. Thesium chinense Turcz. 제비꿀 BS_20180044

\section{POLYGONACEAE 마디풀과}

88. Fagopyrum esculentum Moench 메 밀* BS 20180542

89. Fallopia dentatoalata (F. Schmidt) Holub 큰닭의덩굴 BS_20180915

90. Fallopia dumetorum (L.) Holub 닭의덩굴 BS 20180472 91. Fallopia multiflora (Thunb.) Haraldson 하수오* BS_20180312 92. Persicaria dissitiflora (Hemsl.) H. Gross ex T. Mori 가시여뀌 BS_20180318

93. Persicaria filiformis (Thunb.) Nakai ex T. Mori 이삭여뀌 BS 20180815

94. Persicaria hydropiper (L.) Delarbre 여뀌 BS_20180779

95. Persicaria lapathifolia (L.) Delarbre 흰여뀌 $B S \_20180988$

96. Persicaria longiseta (Bruijn) Kitag. 개여뀌 BS_20180359

97. Persicaria muricata (Meisn.) Nemoto 넓은잎미꾸리낚시 BS_20180311

98. Persicaria orientalis (L.) Spach 털여뀌 BS_20180948

99. Persicaria perfoliata (L.) H. Gross 며느리배꼽 BS_20180545

100. Persicaria posumbu (Buch. Ham. ex D. Don) H. Gross 장대여뀌 BS_20180829

101. Persicaria sagittata (L.) H. Gross 미꾸리낚시 BS_20180574 102. Persicaria senticosa (Meisn.) H. Gross ex Nakai 며느리밑씻개 BS_20180544

103. Persicaria thunbergii (Siebold \& Zucc.) H. Gross 고마리 BS 20180384

104. Persicaria vulgaris Webb \& Moq. 봄여뀌 BS_20180627

105. Polygonum aviculare L. 마디풀 $B S \_20180525$

$\star$ 106. Polygonum bellardii All. 큰옥매듭풀 BS 20180929

107. Rumex acetosella L. 애기수영 BS_20180763

108. Rumex crispus L. 소리쟁이 BS 20180709

109. Rumex japonicus Houtt. 참소리쟁이 BS_20180893

110. Rumex obtusifolius L. 돌소리쟁이 BS_20180492

PHYTOLACCACEAE 자리공과

111. Phytolacca americana L. 미국자리공 BS_20180235

MOLLUGINACEAE 석류풀과

112. Mollugo pentaphylla L. 석류풀 BS_20180232

AIZOACEAE 번행초과

$\star$ 113. Tetragonia tetragonioides (Pall.) Kuntze 번행초 BS_20180607

PORTULACACEAE 쇠비름과

114. Portulaca oleracea L. 쇠비름 BS_20180725

CARYOPHYLLACEAE 석죽과
Appendix 1. Continued.

115. Arenaria serpyllifolia L. 벼룩이자리 BS_20180614

116. Cerastium glomeratum Thuill. 유럽점나도나물 BS 20180805

117. Cerastium holosteoides Fr. var. hallaisanense (Nakai) Mizush. 점나 도나물 BS 20180832

$\star$ 118. Dianthus barbatus L. var. asiaticus Nakai 수염패랭이꽃* BS_20180736

$\star$ 119. Gypsophila oldhamiana Miq. 대나물 BS 20180476

120. Pseudostellaria heterophylla (Miq.) Pax 개별꽃 BS_20180059

$\star$ 121. Sagina maxima A. Gray 큰개미자리 BS_20180910

122. Silene aprica Turcz. var. oldhamiana (Miq.) C. Y. Wu 갯장구채 BS_20180375

$\star$ 123. Spergularia marina (L.) Besser 갯개미자리 BS_20180365

124. Stellaria aquatica (L.) Scop. 쇠별꽃 BS_20180724

125. Stellaria media (L.) Vill. 별꽃 BS_20180617

126. Stellaria uliginosa Murray 벼룩나물 BS_20180613

CHENOPODIACEAE 명아주과

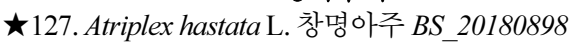

128. Atriplex subcordata Kitag. 갯는쟁이 BS_20180368

129. Chenopodium acuminatum Willd. subsp. virgatum (Thunb.)

C.H.Blom 버들명아주 BS 20180606

130. Chenopodium album L. 흰명아주 BS_20180984

131. Chenopodium album L. var. centrorubrum Makino 명아주 BS_20180546

132. Chenopodium ficifolium $\mathrm{Sm}$. 좀명아주 BS_20180854

$\star$ 133. Kochia scoparia (L.) Schrad. var. littorea Makino 갯댑싸리 BS_20180369

134. Salicornia europaea L. 퉁퉁마디 BS_20180954

$\star$ 135. Salsola kali L. subsp. ruthenica (Iljiin) Soó 나래수송나물 BS_20180441

$\star$ 136. Salsola komarovii Iljin 수송나물 BS_20180733

$\star$ 137. Suaeda australis (R.Br.) Moq. 방석나물 BS_20180594

138. Suaeda glauca (Bunge) Bunge 나문재 BS_20180292

139. Suaeda japonica Makino 칠면초 BS_20180907

$\star$ 140. Suaeda maritima (L.) Dumort. 해홍나물 BS 20180970

AMARANTHACEAE 비름과

$\star$ 141. Achyranthes bidentata Blume 털쇠무릎 BS_20180947

142. Achyranthes bidentata Blume var. japonica Miq. 쇠무를 BS_20180721

143. Amaranthus blitum L. subsp. oleraceus (L.) Costea 개비름 BS_20180220

144. Amaranthus retroflexus L. 털비름 BS_20180946

145. Amaranthus tricolor L. 비름 BS 20180635

$\star$ Ł146. Amaranthus viridis L. 청비름 BS_20180903

MAGNOLIACEAE 목련과

$\star$ 147. Magnolia denudata Desr. 백목련* BS_20180602

$\star$ 148. Magnolia grandiflora L. 태산목* BS_20180937

149. Magnolia obovata Thunb. 일본목련*BS_20180818

LAURACEAE 녹나무과

$\star$ 150. Cinnamomum camphora (L.) J. Presl 녹나무* BS 20180459

151. Lindera erythrocarpa Makino 비목나무 BS_20180636

152. Lindera glauca (Siebold \& Zucc.) Blume 감태나무 BS_20180340

153. Lindera obtusiloba Blume 생강나무 BS_20180692

154. Machilus thunbergii Siebold \& Zucc. 후박나무 BS_20180983

RANUNCULACEAE 미나리아재비과

155. Aconitum jaluense Kom. 투구꽃 BS_20180953

$\star$ 156. Aconitum longecassidatum Nakai 흰진범 BS_20180880

$\star$ 157. Actaea asiatica $\mathrm{H}$. Hara 노루삼 BS_20180456

$\star$ 158. Adonis pseudoamurensis W. T. Wang 개복수초 BS_20180003

159. Anemone raddeana Regel 뀡의바람꽃 BS 20180016

160. Clematis apiifolia DC. 사위질빵 BS_20180270 
Appendix 1. Continued.

161. Clematis fusca Turcz. var. violacea Maxim. 종덩굴 BS_20180151 162. Clematis patens C. Morren \& Decne. 큰꽃으아리 BS_20180095 163. Clematis terniflora DC. var. mandshurica (Rupr.) Ohwi 으아리 BS_20180280

164. Eranthis byunsanensis B. Y. Sun 변산바람꽃 BS_20180001 165. Hepatica asiatica Nakai 노루귀 BS_20180011

166. Pulsatilla koreana (Y. Yabe ex Nakai) Nakai ex T. Mori 할미꽃 BS_20180025

167. Ranunculus cantoniensis DC. 털개구리미나리 BS 20180940

168. Ranunculus chinensis Bunge 젓가락나물 BS 20180835

169. Ranunculus japonicus Thunb. 미나리아재비 BS_20180577

170. Ranunculus sceleratus L. 개구리자리 BS 20180344

171. Semiaquilegia adoxoides (DC.) Makino 개구리발톱 BS_20180063

172. Thalictrum actaeifolium Siebold \& Zucc. 은꿩의다리 BS_20180807

\section{BERBERIDACEAE 매자나무과}

173. Nandina domestica Thunb. 남천* BS 20180447

LARDIZABALACEAE 으름덩굴과

174. Akebia quinata (Houtt.) Decne. 으름덩굴 BS_20180042

MENISPERMACEAE 방기과

175. Cocculus orbiculatus (L.) DC. 댕댕이덩굴 BS_20180253

NYMPHAEACEAE 수련과

176. Nymphaea tetragona Georgi 수련* BS_20180730

NELUMBONACEAE 연꽃과

$\star 177$. Nelumbo nucifera Gaertn. 연꽃* BS 20180781

SAURURACEAE 삼백초과

$\star 178$. Houttuynia cordata Thunb. 약모밀* BS 20180768

$\star$ 179. Saururus chinensis (Lour.) Baill. 삼백초* BS_20180679

CHLORANTHACEAE 홀아비꽃대과

$\star$ 180. Chloranthus fortunei (A. Gray) Solms 옥녀꽃대 BS_20180786

181. Chloranthus japonicus Siebold 홀아비꽃대 BS_20180976

ARISTOLOCHIACEAE 쥐방울덩굴과

182. Aristolochia contorta Bunge 쥐방울덩굴 BS_20180871

183. Asarum maculatum Nakai 개족도리풀 BS 20180049

184. Asarum sieboldii Miq. 족도리풀 BS_20180842

PAEONIACEAE 작약과

$\star$ 185. Paeonia lactiflora Pall. 작약* BS 20180826

ACTINIDIACEAE 다래나무과

186. Actinidia arguta (Siebold \& Zucc.) Planch. ex Miq. 다래 BS_20180466

\section{THEACEAE 차나무과}

187. Camellia japonica L. 동백나무* BS 20180497

188. Eurya japonica Thunb. 사스레피나무 BS_20180650

CLUSIACEAE 물레나물과

189. Hypericum ascyron L. 물레나물 BS_20180560

190. Hypericum erectum Thunb. 고추나물 BS_20180259

191. Hypericum laxum (Blume) Koidz. 좀고추나물 BS_20180276

PAPAVERACEAE 양귀비과

192. Chelidonium majus L. subsp. asiaticum H. Hara 애기똥풀 BS_20180759

193. Corydalis incisa (Thunb.) Pers. 자주괴불주머니 BS_20180824 194. Corydalis remota Fisch. ex Maxim. 현호색 BS_20180974

$\star$ \195. Corydalis turtschaninovii Besser 조선현호색 BS_20180068

$\star$ 196. Papaver rhoeas L. 개양귀비 BS_20180358

\section{BRASSICACEAE 십자화과}

197. Arabis hirsuta (L.) Scop. 털장대 BS_20180163

198. Barbarea orthoceras Ledeb. 나도냉이 BS 20180436

199. Brassica juncea (L.) Czern. 갓 BS_20180341

200. Capsella bursa-pastoris (L.) Medik. 냉이 BS 20180449

201. Cardamine flexuosa With. 황새냉이 BS_20180979
Appendix 1. Continued.

202. Cardamine leucantha (Tausch) O. E. Schulz 미나리냉이 BS_20180576

$\star$ 203. Cardamine manshurica (Kom.) Nakai 애기황새냉이 BS 20180765

204. Cardamine scutata Thunb. 큰황새냉이 BS_20180934

205. Lepidium virginicum L. 콩다닥냉이 BS_20180909

$\star$ 206. Rorippa palustris (L.) Besser 속속이풀 BS 20180713

PLATANACEAE 버즘나무과

$\star 207$. Platanus occidentalis L. 양버즘나무* BS 20180772

CRASSULACEAE 돌나물과

208. Hylotelephium spectabile (Boreau) H. Ohba 큰꿩의비름 BS_20180302

$\star 209$. Phedimus aizoon var. latifolius (Maxim.) H. Ohba 큰기린초 BS 20180914

210. Phedimus kamtschaticus (Fisch. \& C. A. Mey.) 't Hart 기린초 BS_20180101

211. Sedum bulbiferum Makino 말똥비름 BS_20180531

$\star 212$. Sedum oryzifolium Makino 땅채송화 $B S 20180516$

213. Sedum polytrichoides Hemsl. 바위채송화 BS_20180586

214. Sedum sarmentosum Bunge 돌나물 BS_20180491

HYDRANGEACEAE 수국과

215. Philadelphus schrenkii Rupr. 고광나무 BS 20180380

GROSSULARIACEAE 까치밥나무과

216. Ribes fasciculatum Siebold \& Zucc. var. chinense Maxim. 까마귀 밥나무 BS_20180421

\section{PITTOSPORACEAE 돈나무과}

$\star 217$. Pittosporum tobira (Thunb.) W. T. Aiton 돈나무 BS_20180489 ROSACEAE 장미과

$\star$ 218. Agrimonia coreana Nakai 산짚신나물 BS 20180674

$\star 219$. Agrimonia nipponica Koidz. 좀짚신나물 $\bar{B} S \_20180857$

220. Agrimonia pilosa Ledeb. 짚신나물 BS_20180206

221. Chaenomeles sinensis (Thouin) Koehne 모과나무* BS 20180548

222. Crataegus pinnatifida Bunge 산사나무 BS_20180666

$\star$ 223. Duchesnea chrysantha (Zoll. \& Moritzi) Miq. 산뱀딸기 BS 20180662

224. Duchesnea indica (Andrews) Focke 뱀딸기 BS_20180604

225. Geum aleppicum Jacq. 큰뱀무 BS 20180923

226. Malus baccata (L.) Borkh. 야광나무 BS 20180767

227. Photinia villosa (Thunb.) DC. 윤노리나무 BS 20180806

228. Potentilla ancistrifolia Bunge var. dickinsii (Franch. \& Sav.) Koidz. 돌양지 꽃 $B S 20180493$

229. Potentilla discolor Bunge 솜양지꽃 BS 20180718

230. Potentilla fragarioides L. 양지꽃 BS_20180773

231. Potentilla freyniana Bornm. 세 잎양지꽃 BS 20180707

$\star 232$. Potentilla squamosa Soják 털양지꽃 BS_20180036

233. Prunus armeniaca L. 살구나무* BS 20180677

234. Prunus davidiana (Carrière) Franch. 산복사나무 BS_20180664

235. Prunus persica (L.) Stokes 복사나무* BS_20180625

236. Prunus sargentii Rehder 산벚나무 BS_20180663

237. Prunus serrulata Lindl. var. pubescens (Makino) Nakai 잔털벚나 무 BS 20180052

238. Prunus serrulata Lindl. f. spontanea (E. H. Wilson) Chin S. Chang 벚나무*BS_20180612

$\star 239$. Prunus tomentosa Thunb. 앵도나무* BS 20180766

$\star 240$. Pyracantha angustifolia (Franch.) C. K. Schneid. 피라칸다* BS 20180963

241. Pyrus calleryana Decne. var. fauriei (C. K. Schneid.) Rehder 콩배 나무 BS_20180051

242. Rosa lucieae Franch. \& Rochebr. ex Crép. 돌가시나무 BS_20180490 
Appendix 1. Continued.

243. Rosa maximowicziana Regel 용가시나무 BS_20180800

244. Rosa multiflora Thunb. 찔레꽃 BS_20180884

245. Rosa rugosa Thunb. 해당화 BS_20180076

246. Rubus corchorifolius L. f. 수리딸기 BS_20180731

247. Rubus coreanus Miq. 복분자딸기 BS_20180624

248. Rubus crataegifolius Bunge 산딸기 BS_20180658

249. Rubus hirsutus Thunb. 장딸기 BS_20180830

250. Rubus parvifolius L. 멍석딸기 BS_20180539

$\star 251$. Rubus phoenicolasius Maxim. 곰딸기 BS_20180394

$\star 252$. Sanguisorba hakusanensis Makino var. coreana $\mathrm{H}$. Hara 산오이 풀 BS_20180669

253. Sanguisorba officinalis L. 오이풀 BS_20180785

254. Sorbus alnifolia (Siebold \& Zucc.) K. Koch 팥배나무 BS 20180958

255. Spiraea chinensis Maxim. 당조팝나무 BS_20180298

256. Stephanandra incisa (Thunb.) Zabel 국수나무 BS_20180406

FABACEAE 콩과

257. Aeschynomene indica L. 자귀풀 BS_20180821

258. Albizia julibrissin Durazz. 자귀나무 BS 20180820

259. Amorpha fruticosa L. 족제비싸리 BS_20180078

260. Amphicarpaea bracteata (L.) Fernald subsp. edgeworthii (Benth.)

H. Ohashi 새콩 BS_20180690

$\star 261$. Caragana sinica (Buc'hoz) Rehder 골담초* BS_20180390 262. Chamaecrista nomame (Makino) H. Ohashi 차풀 BS_20180885

263. Dunbaria villosa (Thunb.) Makino 여우팥 BS_20180278

264. Gleditsia japonica Miq. 주엽나무* BS_20180862

265. Glycine max (L.) Merr. subsp. soja (Siebold \& Zucc.) H. Ohashi 돌 콩 BS_20180495

266. Hylodesmum oldhamii (Oliv.) H. Ohashi \& R. R. Mill 큰도둑놈의 갈고리 BS_20180917

267. Hylodesmum podocarpum (DC.) H. Ohashi \& R. R. Mill 개도둑놈 의갈고리 $B S 20180347$

268. Hylodesmum podocarpum (DC.) H. Ohashi \& R. R. Mill subsp. oxyphyllum (DC.) H. Ohashi \& R. R. Mill 도둑놈의갈고리 BS_20180487

269. Hylodesmum podocarpum (DC.) H. Ohashi \& R. R. Mill var. mandshuricum (Maxim.) H. Ohashi \& R. R. Mill 애기도둑놈의갈고 리 BS_20180757

270. Indigofera bungeana Walp. 큰낭아초 BS 20180224

271. Indigofera kirilowii Maxim. ex Palib. 땅비싸리 BS_20180515

272. Indigofera koreana Ohwi 좀땅비싸리 BS_20180061

$\star 273$. Kummerowia stipulacea (Maxim.) Makino 둥근매듭풀 BS_20180503

274. Kummerowia striata (Thunb.) Schindl. 매듭풀 BS 20180536

275. Lathyrus japonicus Willd. 갯완두 BS_20180086

276. Lespedeza bicolor Turcz. 싸리 BS_20180262

277. Lespedeza cuneata (Dum. Cours.) G. Don 비수리 BS_20180638

278. Lespedeza cyrtobotrya Miq. 참싸리 BS_20180894

279. Lespedeza maximowiczii C. K. Schneid. 조록싸리 BS_20180839

280. Lespedeza pilosa (Thunb.) Siebold \& Zucc. 괭이싸리 BS_20180402

281. Lespedeza tomentosa (Thunb.) Siebold ex Maxim. 개싸리 BS_20180355

282. Maackia amurensis Rupr. 다릅나무 BS 20180467

$\star$ 283. Medicago minima (L.) Bartal. 좀개자리 BS_20180846

284. Medicago polymorpha L. 개자리 BS_20180363

$\star$ 285. Medicago sativa L. 자주개자리 $B S \_20180822$

286. Pueraria lobata (Willd.) Ohwi 칡 BS_20180175

287. Rhynchosia acuminatifolia Makino 큰여우콩 BS_20180928

288. Robinia pseudoacacia L. 아까시나무 BS_20180749
Appendix 1. Continued.

289. Sophora flavescens Aiton 고삼 BS_20180388

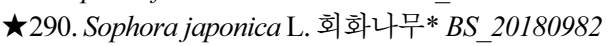

291. Trifolium repens L. 토끼풀 BS_20180951

292. Vicia amoena Fisch. ex Ser. 갈퀴나물 BS 20180337

293. Vicia angustifolia L. ex Reichard var. segetilis (Thuill.) W.D.J.Koch 살갈퀴 BS_20180031

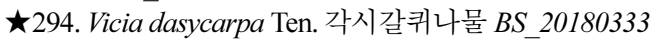

295. Vicia hirsuta (L.) Gray 새완두 BS_20180688

$\star 296$. Vicia hirticalycina Nakai 나래완두 BS 20180442

297. Vicia tetrasperma (L.) Schreb. 얼치기완두 BS_20180033

298. Vicia venosa (Link) Maxim. var. cuspidata Maxim. 광릉갈퀴 BS 20180399

299. Vigna angularis (Willd.) Ohwi \& H. Ohashi var. nipponensis (Ohwi) Ohwi \& H. Ohashi 새팥 BS_20180314

$\star 300$. Vigna nakashimae (Ohwi) Ohwi \& H. Ohashi 좀돌팥 BS_20180282

301. Wisteria floribunda (Willd.) DC. 등* BS_20180512

OXALIDACEAE 갱이밥과

302. Oxalis corniculata L. 괭이밥 BS_20180401

$\star$ 303. Oxalis dillenii Jacq. 들괭이밥 BS_20180508

$\star$ 304. Oxalis stricta L. 선괭이밥 BS_20180700

GERANIACEAE 쥐손이풀과

305. Geranium thunbergii Siebold ex Lindl. \& Paxton 이질풀 BS 20180816

306. Geranium wilfordii Maxim. 세잎쥐손이 BS_20180708

\section{EUPHORBIACEAE 대극과}

307. Acalypha australis L. 깨풀 BS_20180423

308. Euphorbia humifusa Willd. ex Schltdl. 땅빈대 BS_20180191

$\star$ 309. Euphorbia marginata Pursh 설악초* BS 20180705

310. Euphorbia sieboldiana Morren \& Decne. 개감수 BS_20180137

311. Euphorbia supina Raf. 애기땅빈대 BS_20180758

312. Mallotus japonicus (L.f.) Müll.Arg. 예덕나무 BS 20180169

313. Neoshirakia japonica (Siebold \& Zucc.) Esser 사람주나무 BS_20180100

314. Phyllanthus ussuriensis Rupr. \& Maxim. 여우주머니

BS_20180234

315. Securinega suffruticosa (Pall.) Rehder 광대싸리 BS_20180159

$\star$ 316. Ricinus communis L. 피마자*BS_20180964

RUTACEAE 운향과

317. Orixa japonica Thunb. 상산 BS_20180683

318. Poncirus trifoliatus (L.) Raf. 탱자나무* BS_20180939

319. Zanthoxylum piperitum (L.) DC. 초피나무 BS_20180904

320. Zanthoxylum schinifolium Siebold \& Zucc. 산초나무 BS_20180255

\section{SIMAROUBACEAE 소태나무과}

321. Ailanthus altissima (Mill.) Swingle 가죽나무* BS_20180332

322. Picrasma quassioides (D. Don) Benn. 소태나무 BS_20180712 MELIACEAE 멀구슬나무과

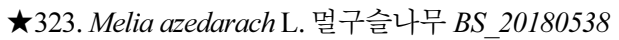

324. Toona sinensis (Juss.) M. Roem. 참죽나무* BS_20180896

ANACARDIACEAE 옻나무과

325. Rhus chinensis Mill. 붉나무 BS_20180630

326. Toxicodendron sylvestre (Siebold \& Zucc.) Kuntze 산검양옻나무 BS_20180654

327. Toxicodendron trichocarpum (Miq.) Kuntze 개옻나무 BS_20180361

328. Toxicodendron vernicifluum (Stokes) F. A. Barkley 옻나무* BS_20180791

ACERACEAE 단풍나무과

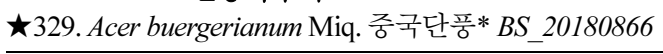


Appendix 1. Continued.

330. Acer palmatum Thunb. 단풍나무 BS_20180126

331. Acer pictum Thunb. var. mono (Maxim.) Maxim. ex Franch. 고로 쇠나무 BS_20180383

332. Acer pseudosieboldianum (Pax) Kom. 당단풍나무 BS_20180024

333. Acer tataricum L. subsp. ginnala (Maxim.) Wesm. 신나무 BS_20180742

334. Acer triflorum Kom. 복자기 BS 20180626

$\star 335$. Acer truncatum Bunge f. barbinerve (Nakai) M. Kim 털만주고 로쇠 BS 20180943

SAPINDACEAE 무환자나무과

336. Koelreuteria paniculata Laxm. 모감주나무* BS_20180547

SABIACEAE 나도밤나무과

337. Meliosma myriantha Siebold \& Zucc. 나도밤나무 BS_20180205

338. Meliosma pinnata (Roxb.) Maxim. var. oldhamii (Miq. ex Maxim.)

Beusekom 합다리나무 BS 20180128

BALSAMINACEAE 봉선화과

339. Impatiens textorii Miq. 물봉선 BS_20180562

AQUIFOLIACEAE 감탕나무과

340. Ilex cornuta Lindl. \& Paxton 호랑가시나무 BS 20180017

341. Ilex crenata Thunb. 꽝꽝나무 BS_20180108

\section{CELASTRACEAE 노박덩굴과}

342. Celastrus orbiculatus Thunb. 노박덩굴 BS 20180458

343. Euonymus alatus (Thunb.) Siebold 화살나무 BS 20180977

344. Euonymus alatus (Thunb.) Siebold f. ciliato-dentatus (Franch. \&

Sav.) Hiyama 회잎나무 BS_20180022

345. Euonymus hamiltonianus Wall. var. maackii (Rupr.) Kom. 좀참빗 살나무 $B S \_20180858$

346. Euonymus japonicus Thunb. 사철나무* BS_20180651

347. Euonymus oxyphyllus Miq. 참회나무 BS 20180023

STAPHYLEACEAE 고추나무과

348. Euscaphis japonica (Thunb.) Kanitz 말오줌때 BS_20180532

349. Staphylea bumalda DC. 고추나무 BS_20180168

BUXACEAE 회양목과

350. Buxus sinica (Rehder \& E. H. Wilson) M. Cheng var. koreana

(Nakai ex Rehder) Q. L. Wang 회양목 BS_20180981

RHAMNACEAE 갈매나무과

351. Rhamnella franguloides (Maxim.) Weberb. 까마귀베개 BS_20180149

352. Rhamnus yoshinoi Makino 짝자래나무 BS 20180882

353. Zizyphus jujuba var. inermis (Bunge) Rehder 대추나무* BS 20180480

\section{VITACEAE 포도과}

354. Ampelopsis brevipedunculata (Maxim.) Trautv. f. citrulloides

(Lebas) Rehder 가새잎개머루 BS 20180329

355. Ampelopsis heterophylla (Thunb.) Siebold \& Zucc. 개머루 BS_20180177

356. Parthenocissus tricuspidata (Siebold \& Zucc.) Planch. 담쟁이덩굴 BS_20180475

$\star$ 357. Parthenocissus quinquefolia (L.) Planch. 미국담쟁이덩굴 BS_20180570

358. Vitis amurensis Rupr. 왕머루 BS_20180161

359. Vitis flexuosa Thunb. 새머루 BS_20180093

360. Vitis heyneana Roem. \& Schult. subsp. ficifolia (Bunge) C. L. Li 까 마귀머루 BS_20180240

\section{TILIACEAE 피나무과}

361. Corchoropsis tomentosa (Thunb.) Makino 수까치깨 BS_20180728

362. Grewia biloba G. Don 장구밥나무 BS_20180828

363. Tilia mandshurica Rupr. \& Maxim. 찰피나무 BS_20180886

364. Tilia miqueliana Maxim. 보리자나무* BS_20180623

MALVACEAE 아욱과
Appendix 1. Continued.

365. Abutilon theophrasti Medik. 어저귀 BS_20180777

366. Althaea rosea Cav. 접시꽃* BS 20180834

367. Hibiscus syriacus L. 무궁화* BS_20180553

368. Malva verticillata L. 아욱* BS 20180750

STERCULIACEAE 벽오동과

369. Firmiana simplex (L.) W. Wight 벽오동나무* BS_20180615

THYMELAEACEAE 팥꽃나무과

370. Daphne genkwa Siebold \& Zucc. 팥꽃나무 BS_20180957

ELAEAGNACEAE 보리수나무과

371. Elaeagnus macrophylla Thunb. 보리밥나무 BS 20180621

372. Elaeagnus multiflora Thunb. 뜰보리수*BS_20180522

373. Elaeagnus umbellata Thunb. 보리수나무 BS_20180622

FLACOURTIACEAE 이나무과

374. Idesia polycarpa Maxim. 이나무 BS_20180112

VIOLACEAE 제비꽃과

375. Viola acuminata Ledeb. 졸방제비꽃 BS 20180843

376. Viola albida Palib. var. chaerophylloides (Regel) F. Maek. ex

H.Hara 남산제비꽃 BS_20180446

$\star$ 377. Viola albida Palib. var. takahashii (Makino) Nakai 단풍제비꽃 BS_20180468

378. Viola arcuata Blume 콩제비꽃 BS_20180026

379. Viola grypoceras A. Gray 낚시제비꽃 BS_20180444

380. Viola japonica Langsd. ex DC. 왜제비꽃 BS_20180799

$\star$ 381. Viola lactiflora Nakai 흰젖제비꽃 BS 20180989

382. Viola mandshurica W. Becker 제비꽃 $B \bar{S} 20180836$

383. Viola patrinii DC. ex Ging. 흰제비꽃 BS_20180990

384. Viola rossii Hemsl. 고깔제비꽃 BS 20180381

385. Viola violacea Makino 자주잎제비꽃 BS_20180825

CUCURBITACEAE 박과

386. Actinostemma lobatum (Maxim.) Maxim. ex Franch. \& Sav. 뚜껑

덩굴 BS_20180184

387. Citrullus vulgaris Schrad. 수박* BS 20180732

388. Gynostemma pentaphyllum (Thunb.) Makino 돌외 BS_20180494

$\star$ 389. Melothria japonica (Thunb.) Maxim. ex Cogn. 새박

BS 20180686

$\star$ 390. Schizopepon bryoniifolius Maxim. 산외 BS_20180670

391. Trichosanthes kirilowii Maxim. 하늘타리 BS_20180967

LYTHRACEAE 부처꽃과

\392. Ammannia multiflora Roxb. 좀부처꽃 BS 20180856

393. Lagerstroemia indica L. 배롱나무* BS_20180597

$\star$ 394. Lythrum salicaria L. 털부처꽃 BS 20180945

$\star$ 395. Rotala indica (Willd.) Koehne 마디꽃 BS_20180524

TRAPACEAE 마름과

$\star$ 396. Trapa japonica Flerow 마름 BS 20180526

ONAGRACEAE 바늘꽃과

397. Ludwigia prostrata Roxb. 여뀌바늘 BS 20180780

398. Oenothera biennis L. 달맞이꽃 BS 20180470

HALORAGACEAE 개미탑과

399. Haloragis micrantha (Thunb.) R. Br. ex Siebold \& Zucc. 개미탑 BS_20180226

ALANGIACEAE 박쥐나무과

400. Alangium platanifolium (Siebold \& Zucc.) Harms var. trilobum

(Miq.) Ohwi 박쥐나무 BS_20180116

CORNACEAE 충충나무과

401. Cornus controversa Hemsl. 층층나무 BS_20180906

402. Cornus kousa F. Buerger ex Hance 산딸나무 BS 20180659

403. Cornus macrophylla Wall. 곰의말채나무 BS 20180397

404. Cornus officinalis Siebold \& Zucc. 산수유* BS_20180667

ARALIACEAE 두릅나무과

405. Aralia elata (Miq.) Seem. 두릅나무 BS_20180499 
Appendix 1. Continued.

\406. Dendropanax trifidus (Thunb.) Makino ex H. Hara 황칠나무* BS_20180980

$\star$ 407. Eleutherococcus divaricatus (Siebold \& Zucc.) S. Y. Hu 털오갈 피나무 BS_20180949

408. Eleutherococcus sessiliflorus (Rupr. \& Maxim.) S. Y. Hu 오갈피나 무*BS_20180784

409. Hedera rhombea (Miq.) Siebold \& Zucc. ex Bean 송악 BS_20180719

410. Kalopanax septemlobus (Thunb.) Koidz. 음나무 BS_20180812

APIACEAE 산형과

411. Angelica dahurica (Fisch. ex Hoffm.) Benth. \& Hook. f. ex Franch. \& Sav. 구릿대 BS 20180404

$\star$ 412. Cnidium japonicum Miq. 갯사상자 BS_20180371

413. Cryptotaenia japonica Hassk. 파드득나물 BS_20180956

414. Glehnia littoralis F. Schmidt ex Miq. 갯방풍 BS_20180088

415. Heracleum moellendorffii Hance 어수리 BS_20180776

416. Hydrocotyle maritima Honda 선피막이 BS 20180704

417. Hydrocotyle ramiflora Maxim. 큰피막이 BS_20180244

418. Oenanthe javanica (Blume) DC. 미나리 BS_20180575

419. Osmorhiza aristata (Thunb.) Rydb. 긴사상자 BS_20180120

420. Ostericum grosseserratum (Maxim.) Kitag. 신감채 BS_20180741

421. Sanicula chinensis Bunge 참반디 BS_20180889

422. Torilis japonica (Houtt.) DC. 사상자 BS_20180649

423. Torilis scabra (Thunb.) DC. 개사상자 BS 20180353

ERICACEAE 진달래과

^424. Monotropastrum humile (D. Don) H. Hara 나도수정초 BS_20180439

425. Pyrolajaponica Klenze ex Alef. 노루발 BS_20180455

426. Rhododendron indicum (L.) Sweet 영산홍* BS 20180782

427. Rhododendron mucronulatum Turcz. 진달래 $B \bar{S} 20180878$

428. Rhododendron schlippenbachii Maxim. 철쭉 BS_20180053

429. Vaccinium oldhamii Miq. 정금나무 BS_20180118

MYRSINACEAE 자금우과

430. Ardisia japonica (Thunb.) Blume 자금우 BS 20180007

\section{PRIMULACEAE 앵초과}

431. Lysimachia clethroides Duby 큰까치수염 BS_20180135

432. Lysimachia japonica Thunb. 좀가지풀 BS_20180844

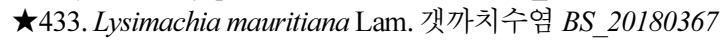

PLUMBAGINACEAE 갯질경과

434. Limonium tetragonum (Thunb.) Bullock 갯질경 BS_20180376

\section{EBENACEAE 감나무과}

435. Diospyros kaki L. f. 감나무* BS 20180339

436. Diospyros lotus L. 고욤나무 BS_20180389

\section{STYRACACEAE 때죽나무과}

437. Styrax japonicus Siebold \& Zucc. 때죽나무 BS_20180517 438. Styrax obassis Siebold \& Zucc. 쪽동백나무 BS_20180883 SYMPLOCACEAE 노린재나무과

439. Symplocos sawafutagi Nagam. 노린재나무 BS_20180457 440. Symplocos tanakana Nakai 검노린재나무 BS_20180377

\section{OLEACEAE 물푸레나무과}

441. Abeliophyllum distichum Nakai 미선나무 BS_20180579

442. Forsythia koreana (Rehder) Nakai 개나리* BS_20180346

443. Fraxinus rhynchophylla Hance 물푸레나무 BS_20180565

444. Fraxinus sieboldiana Blume 쇠물푸레나무 BS_20180722

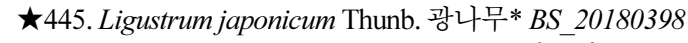

446. Ligustrum obtusifolium Siebold \& Zucc. 쥐똥나무 BS_20180099

$\star$ 447. Ligustrum quihoui Carrière var. latifolium Nakai 상동잎쥐똥나

무 BS_20180682

448. Osmanthus heterophyllus (G. Don) P. S. Green 구골나무* BS_20180403
Appendix 1. Continued.

\section{LOGANIACEAE 마전과}

449. Mitrasacme pygmaea R. Br. 큰벼룩아재비 BS 20180222

GENTIANACEAE 용담과

450. Gentiana zollingeri Fawc. 큰구슬붕이 BS_20180070

\section{MENYANTHACEAE 조름나물과}

$\star$ 451. Nymphoides indica (L.) Kuntze 어리연 꽃 BS_20180775

$\star$ 452. Nymphoides peltata (S. G. Gmel.) Kuntze 노랑어리연 꽃 BS_20180454

\section{APOCYNACEAE 협죽도과}

453. Cynanchum paniculatum (Bunge) Kitag. ex H. Hara 산해박 BS_20180676

454. Metaplexis japonica (Thunb.) Makino 박주가리 BS_20180587 455. Trachelospermum asiaticum (Siebold \& Zucc.) Nakai 마삭줄 BS 20180527

\section{RUBIACEAE 꼭두서니과}

456. Galium gracilens (A. Gray) Makino 좀네잎갈퀴 BS_20180849

$\star$ 457. Galium kinuta Nakai \& H. Hara 검은개선갈퀴 BS_20180378

458. Galium pogonanthum Franch. \& Sav. 산갈퀴 BS_20180653

459. Galium spurium L. 갈퀴덩굴 BS_20180338

460. Galium verum L. 솔나물 BS_20180715

461. Mitchella undulata Siebold \& Zucc. 호자덩굴 BS_20180131

462. Paederia foetida L. 계요등 BS_20180193

463. Rubia argyi (H. Lév. \& Vaniot) H. Hara ex Lauener 꼭두서니 BS_20180426

464. Rubia cordifolia L. 갈퀴꼭두서니 BS_20180336

POLEMONIACEAE 꽃고비과

465. Phlox subulata L. 지면패랭이*BS_20180876

CONVOLVULACEAE 메꽃과

466. Calystegia hederacea Wall. 애기메꽃 BS 20180760

$\star$ 467. Calystegia pellita (Ledeb.) G. Don 선메꽃 BS_20180701

468. Calystegia pubescens Lindl. 메꽃 BS_20180541

469. Calystegia sepium (L.) R. Br. 큰메꽃 BS_20180921

470. Calystegia soldanella (L.) R. Br. 갯메꽃 BS_20180074

471. Cuscuta australis $\mathrm{R}$. Br. 실새삼 BS 20180743

472. Cuscuta japonica Choisy 새삼 BS_20180687

473. Cuscuta pentagona Engelm. 미국실새삼 BS_20180571

$\star$ 474. Ipomoea lacunosa L. 애기나팔꽃 BS_20180755

475. Ipomoea nil (L.) Roth 나팔꽃 BS_20180443

476. Ipomoea purpurea (L.) Roth 둥근잎나팔꽃 BS_20180504

477. Quamoclit angulata (Lam.) Bojer 둥근잎유홍초 BS_20180505

BORAGINACEAE 지치과

478. Argusia sibirica (L.) Dandy 모래지치 BS 20180090

479. Bothriospermum tenellum (Hornem.) Fisch. \& C. A. Mey. 꽃받이 BS_20180040

480. Lithospermum zollingeri A. DC. 반디지치 BS 20180590

481. Trigonotis peduncularis (Trevis.) Benth. ex Baker \& S. Moore 꽃마 리 BS_20180428

\section{VERBENACEAE 마편초과}

482. Callicarpa japonica Thunb. 작살나무 BS 20180102 483. Callicarpa mollis Siebold \& Zucc. 새비나무 BS_20180110 484. Caryopteris incana (Thunb. ex Houtt.) Miq. 층꽃나무 BS_20180299

485. Clerodendrum trichotomum Thunb. 누리장나무 BS_20180460 486. Vitex rotundifolia L.f. 순비기나무 BS 20180290

\section{LAMIACEAE 꿀풀과}

487. Agastache rugosa (Fisch. \& C. A. Mey.) Kuntze 배초향 BS_20180599

488. Ajuga decumbens Thunb. 금창초 BS_20180413

489. Clinopodium chinense (Benth.) Kuntze var. shibetchense (H. Lév.)

Koidz. 산층층이 BS_20180675 
Appendix 1. Continued.

490. Clinopodium multicaule (Maxim.) Kuntze 탑꽃 BS_20180936

$\star$ 491. Elsholtzia byeonsanensis M. Kim 변산향유 BS_20180616 492. Elsholtzia ciliata (Thunb.) Hyl. 향유 BS_20180973 493. Glechoma longituba (Nakai) Kuprian. 긴병꽃풀 BS 20180419 494. Isodon inflexus (Thunb.) Kudô 산박하 BS_20180661 495. Lamium amplexicaule L. 광대나물 BS_20180027 ^496. Lamium purpureum L. 자주광대나물 BS_20180823 497. Leonurus japonicus Houtt. 익모초 BS_20180237 498. Meehania urticifolia (Miq.) Makino 벌깨덩굴 BS_20180609 $\star$ 499. Mentha arvensis L. var. piperascens Malinv. ex Holmes 박하 BS_20180588

500. Mosla scabra (Thunb.) C. Y. Wu \& H. W. Li 들깨풀 BS 20180510 501. Perilla frutescens (L.) Britton var. crispa (Thunb.) H. Deane 소엽* BS_20180710

502. Perilla frutescens var. japonica (Hassk.) Hara 들깨* BS_20180509 503. Prunella vulgaris L. subsp. asiatica (Nakai) H. Hara 꿀풀 BS_20180433

504. Salvia plebeia R. Br. 배암차즈기 BS_20180598

505. Scutellaria indica L. 골무꽃 BS_20180391

$\star$ 506. Scutellaria indica L. var. tsusimensis (H. Hara) Ohwi 떡잎골무 꽃 BS_20180519

507. Scutellaria pekinensis Maxim. var. transitra (Makino) H. Hara 산골 무꽃 BS_20180655

508. Stachys riederi Cham. var. japonica (Miq.) H. Hara 석잠풀 BS_20180699

\section{SOLANACEAE 가지과}

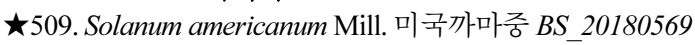

510. Solanum lyratum Thunb. 배풍등 BS_20180600

SCROPHULARIACEAE 현삼과

$\star$ 511. Lindernia dubia (L.) Pennell 미국외풀 BS_20180242

512. Lindernia procumbens (Krock.) Philcox 밭뚝외풀 BS_20180596

$\star$ 513. Mazus miquelii Makino 누운주름잎 BS_20180461

514. Mazus pumilus (Burm. f.) Steenis 주름잎 BS_20180860

515. Melampyrum roseum Maxim. 꽃며느리밥풀 BS_20180429

516. Veronica arvensis L. 선개불알풀 $B S \_20180029$

$\star 517$. Veronica hederifolia L. 눈개불알풀 BS_20180462

518. Veronica persica Poir. 큰개불알풀 BS_20180911

519. Veronica polita $\mathrm{Fr}$. 개불알풀 BS_20180352

BIGNONIACEAE 능소화과

$\star 520$. Catalpa bignonioides Walter 꽃개오동* BS_20180427

521. Catalpa ovata G. Don 개오동* BS_20180360

ACANTHACEAE 쥐꼬리망초과

522. Justicia procumbens L. 쥐꼬리망초 BS_20180868

OROBANCHACEAE 열당과

$\star$ 523. Monochasma sheareri (S. Moore) Maxim. ex Franch. \& Sav. 치 자풀 BS_20180991

\section{PHRYMACEAE 파리풀과}

524. Phryma leptostachya L. var. oblongifolia (Koidz.) Honda 파리풀 BS_20180197

\section{PLANTAGINACEAE 질경이과}

$\star 525$. Callitriche palustris L. 물별이끼 BS_20180561

526. Plantago asiatica L. 질경이 BS_20180881

527. Plantago major L. var. japonica (Franch. \& Sav.) Miyabe 왕질경이 BS_20180796

$\star 528$. Plantago virginica L. 미국질경이 BS_20180573

\section{CAPRIFOLIACEAE 인동과}

529. Lonicera harae Makino 길마가지나무 BS_20180420

530. Lonicera japonica Thunb. 인동덩굴 BS_20180817

531. Lonicera praeflorens Batalin 올괴불나무 BS 20180789

532. Lonicera subsessilis Rehder 청괴불나무 BS_20180901
Appendix 1. Continued.

533. Sambucus racemosa L. subsp. kamtschatica (E. Wolf) Hultén 지렁 쿠나무 BS_20180874

534. Sambucus williamsii Hance 딱총나무 BS_20180514

535. Viburnum dilatatum Thunb. 가막살나무 BS_20180327

536. Viburnum erosum Thunb. 덜뀡나무 BS_20180483

537. Viburnum opulus L. var. calvescens (Rehder) H. Hara 백당나무 BS_20180601

538. Weigela subsessilis (Nakai) L. H. Bailey 병꽃나무 BS_20180619 VALERIANACEAE 마타리과

539. Patrinia scabiosifolia Fisch. ex Trevir. 마타리 BS_20180528

540. Patrinia villosa (Thunb.) Juss. 뚝갈 BS_20180260

CAMPANULACEAE 초롱꽃과

541. Asyneuma japonicum (Miq.) Briq. 영아자 BS_20180783

542. Codonopsis lanceolata (Siebold \& Zucc.) Benth. \& Hook.f. ex

Trautv. 더덕 BS 20180481

543. Lobelia chinensis Lour. 수염가래꽃 BS_20180268

544. Platycodon grandiflorus (Jacq.) A. DC. 도라지 BS_20180488

ASTERACEAE 국화과

545. Ainsliaea acerifolia Sch. Bip. 단풍취 BS_20180469

546. Ainsliaea apiculata Sch. Bip. 좀딱취 BS_20180852

547. Ambrosia artemisiifolia L. 돼지풀 BS_20180498

548. Artemisia annua L. 개똥쑥 BS 20180348

549. Artemisia capillaris Thunb. 사철쑥 BS_20180652

$\star$ 550. Artemisia fauriei Nakai 애기비쑥 BS_20180762

$\star 551$. Artemisia fukudo Makino 큰비쑥 BS_20180925

552. Artemisia indica Willd. 쑥 BS_20180747

553. Artemisia japonica Thunb. 제비쑥 BS_20180837

554. Artemisia keiskeana Miq. 맑은대쑥 $B \bar{S} \_20180534$

$\star 555$. Artemisia lancea Vaniot 뺑쑥 BS_20180641

$\star$ 556. Artemisia sacrorum Ledeb. var. iwayomogi (Kitam.) M .S. Park \& G. Y. Chung 더위지기 BS_20180482

557. Artemisia stolonifera (Maxim.) Kom. 넓은잎외잎쑥 BS 20180451

558. Aster ageratoides Turcz. 까실쑥부쟁이 BS_20180315

559. Aster hispidus Thunb. 갯쑥부쟁이 BS_20180374

560. Aster incisus Fisch. 가새쑥부쟁이 BS_20180328

561. Aster meyendorffii (Regel \& Maack) Voss 개쑥부쟁이

BS_20180357

562. Aster scaber Thunb. 참취 BS_20180897

$\star 563$. Aster spathulifolius Maxim. 해국 BS_20180969

564. Aster tripolium L. 갯개미취 BS_20180366

565. Aster yomena (Kitam.) Honda 쑥부쟁이 BS_20180748

566. Atractylodes ovata (Thunb.) DC. 삽주 BS_20180680

567. Bidens bipinnata L. 도깨비바늘 BS_20180484

$\star$ 568. Bidens biternata (Lour.) Merr. \& Sherff ex Sherff 털도깨비바늘 BS_20180942

569. Bidens frondosa L. 미국가막사리 BS_20180567

$\star$ 570. Bidens pilosa L. 울산도깨비바늘 $B S \_20180803$

571. Bidens tripartita L. 가막사리 BS_20180326

572. Breea segeta (Bunge) Kitam. 조뱅이 BS_20180841

573. Carduus crispus L. 지느러미엉겅퀴 BS_20180873

574. Carpesium abrotanoides L. 담배풀 BS_20180474

575. Carpesium cernuum L. 좀담배풀 BS_20180294

576. Carpesium divaricatum Siebold \& Zucc. 긴담배풀 BS_20180418

$\star 577$. Centaurea cyanus L. 수레국화* BS_20180729

578. Centipeda minima (L.) A. Braun \& Asch. 중대가리풀 BS 20180867

579. Chrysanthemum boreale (Makino) Makino 산국 BS_20180656

580. Chrysanthemum zawadskii Herbich var. latilobum (Maxim.) Kitam.

구절초 $B S 20180405$

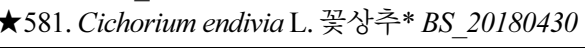


Appendix 1. Continued.

582. Cirsium japonicum Fisch. ex DC. var. maackii (Maxim.) Matsum. 엉겅퀴 BS_20180157

583. Cirsium pendulum Fisch. ex DC. 큰엉겅 퀴 BS_20180927

584. Conyza canadensis (L.) Cronquist 망초 BS 20180535

$\star$ 585. Coreopsis drumondii Torr. \& A. Gray 금계국 BS 20180409

586. Coreopsis lanceolata L. 큰금계국 BS_20180912

$\star 587$. Coreopsis tinctoria Nutt. 기생초 $B \bar{S} 20180416$

588. Cosmos bipinnatus Cav. 코스모스 BS_20180908

589. Crassocephalum crepidioides (Benth.) S. Moore 주홍서나물 BS 20180863

590. Crepidiastrum denticulatum (Houtt.) J. H. Pak \& Kawano 이고들

빼기 BS_20180813

591. Crepidiastrum sonchifolium (Maxim.) J. H. Pak \& Kawano 고들빼

기 $B S 20180382$

592. Eclipta prostrata (L.) L. 한련초 BS_20180968

593. Erechtites hieraciifolius (L.) Raf. ex DC. 붉은서나물

BS 20180632

594. Erigeron annuus (L.) Pers. 개망초 BS_20180133

595. Erigeron floribundus (Kunth) Sch. Bip. 큰망초 BS 20180919

$\star 596$. Erigeron strigosus Muhl. ex Willd. 주걱개망초 $B S \_20180859$

597. Euchiton japonicus (Thunb.) Holub 풀솜나물 BS_20180962

598. Eupatorium japonicum Thunb. 등골나물 BS 20180513

599. Eupatorium makinoi Kawah. \& Yahara var. oppositifolium (Koidz.)

Kawah. \& Yahara 벌등골나물 BS 20180610

600. Eupatorium tripartitum (Makino) Murata \& H. Koyama 향등골나

물 BS_20180972

601. Galinsoga ciliata (Raf.) S. F. Blake 털별꽃아재비 BS_20180944

$\star 602$. Gnaphalium uliginosum L. 왜떡쑥 BS_20180797

603. Helianthus tuberosus L. 뚱딴지 BS 20180521

604. Hemistepta lyrata (Bunge) Bunge 지칭개 BS 20180877

605. Hypochaeris radicata L. 서양금혼초 BS_20180694

$\star 606$. Inula japonica Thunb. 금불초 BS_20180412

607. Ixeridium dentatum (Thunb.) Tzvelev 씀바귀 BS 20180083

608. Ixeridium dentatum (Thunb.) Tzvelev f. albiflora (Makino) H. Hara

흰씀바귀 BS 20180987

609. Ixeris debilis (Thunb.) A. Gray 벋음씀바귀 BS_20180608

610. Ixeris polycephala Cass. 벌씀바귀 BS_20180611

611. Ixeris strigosa (H. Lév. \& Vaniot) J. H. Pak \& Kawano 선씀바귀 BS_20180703

612. Lactuca indica L. 왕고들빼기 BS_20180792

613. Lactuca indica L. var. laciniata (Houtt.) H. Hara f. indivisa

(Maxim.) H. Hara 가는잎왕고들 빼기 BS 20180324

614. Lactuca raddeana Maxim. 산씀바귀 BS_20180668

615. Lactuca serriola L. 가시상추 BS 20180330

$\star$ 616. Lactuca triangulata Maxim. 두메고들빼기 BS_20180500

$\star$ 617. Lapsana communis L. 서양개보리 뺑이 BS_20180693

618. Leibnitzia anandria (L.) Turcz. 솜나물 BS 20180716

619. Petasites japonicus (Siebold \& Zucc.) Maxim. 머위 BS_20180537

$\star 620$. Picris hieracioides L. subsp. japonica (Thunb.) Hand.-Mazz. 쇠

서나물 BS_20180726

621. Pseudognaphalium affine (D. Don) Anderb. 떡쑥 BS_20180103

622. Rudbeckia bicolor Nutt. 원추천인국 BS 20180804

$\star 623$. Senecio vulgaris L. 개쑥갓 BS_20180356

624. Sigesbeckia glabrescens (Makino) Makino 진득찰 BS_20180879

625. Sigesbeckia orientalis L. subsp. pubescens (Makino) H. Koyama 털

진득찰 $B S 20180950$

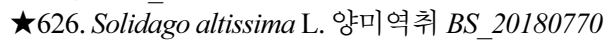

627. Solidago virgaurea L. subsp. asiatica Kitam. ex H. Hara 미역취 BS 20180580

628. Sonchus asper (L.) Hill 큰방가지똥 BS_20180922
Appendix 1. Continued.

629. Sonchus brachyotus DC. 사데풀 BS_20180647

$\star$ 630. Symphyotrichum expansum (Poepp. ex Spreng.) G.L.Nesom 큰 비짜루국화 $B S 20180926$

$\star 631$. Symphyotrichum pilosum (Willd.) G. L. Nesom 미국쑥부쟁이 BS_20180572

$\star$ 632. Symphyotrichum subulatum (Michx.) G. L. Nesom 비짜루국화 BS_20180640

633. Syneilesis palmata (Thunb.) Maxim. 우산나물 BS_20180802

634. Tagetes minuta L. 만수국아재비 BS 20180530

$\star 635$. Tagetes patula L. 만수국* BS_20180529

636. Taraxacum coreanum Nakai 흰민들레 BS_20180985

637. Taraxacum officinale F. H. Wigg. 서양민들레 BS 20180695

638. Taraxacum platycarpum Dahlst. 민들레 BS_20180581

$\star 639$. Xanthium orientale L. 큰도꼬마리 BS 20180916

640. Xanthium strumarium L. 도꼬마리 BS 20180486

641. Youngia japonica (L.) DC. 뽀리뱅이 BS_20180643

ALISMATACEAE 택사과

642. Alisma canaliculatum A. Braun \& C. D. Bouché 택사 BS 20180938

HYDROCHARITACEAE 자라풀과

$\star 643$. Hydrilla verticillata (L. f.) Royle 검정말 BS_20180379

POTAMOGETONACEAE 가래과

$\star 644$. Potamogeton crispus L. 말즘 BS_20180533

NAJADACEAE 나자스말과

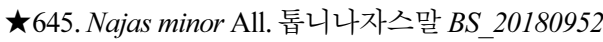

\section{LILIACEAE 백합과}

646. Allium macrostemon Bunge 산달래 BS 20180657

647. Allium thunbergii G. Don 산부추 BS_20180891

648. Asparagus cochinchinensis (Lour.) Merr. 천문동 BS 20180073

649. Asparagus schoberioides Kunth 비짜루 BS_20180639

650. Barnardia japonica (Thunb.) Schult.f. 무릇 BS_20180554

651. Disporum smilacinum A. Gray 애기나리 BS 20180754

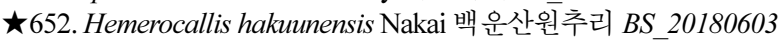
653. Hosta capitata (Koidz.) Nakai 일월비비추 BS 20180819 654. Hosta longipes (Franch. \& Sav.) Matsum. 비비추* BS_20180637 $\star 655$. Hosta plantaginea (Lam.) Asch. 옥잠화* BS_20180788 656. Lilium amabile Palib. 털중나리 BS_20180147

657. Lilium lancifolium Thunb. 참나리 BS_20180887 658. Lilium tsingtauense Gilg 하늘 말나리 BS 20180965 659. Liriope muscari (Decne.) L. H. Bailey 맥문동* BS_20180203 660. Liriope spicata (Thunb.) Lour. 개맥문동 BS_20180349 661. Ophiopogon japonicus (Thunb.) Ker Gawl. 소엽맥문동 BS_20180711

662. Paris verticillata M. Bieb. 삿갓나물 BS 20180681 663. Polygonatum lasianthum Maxim. 죽대 $\bar{B} S \_20180864$ 664. Polygonatum odoratum (Mill.) Druce var. pluriflorum (Miq.) Ohwi

둥굴레 $B S 20180502$

665. Smilax china L. 청미래덩굴 BS_20180038

666. Smilax nipponica Miq. 선밀나물 BS_20180702

667. Smilax sieboldii Miq. 청가시덩굴 $B \bar{S} 20180900$

668. Tricyrtis macropoda Miq. 뻐꾹나리 BS_20180642

669. Tulipa edulis (Miq.) Baker 산자고 BS 20180671

AGAVACEAE 용설란과

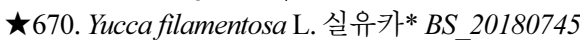

AMARYLLIDACEAE 수선화과

671. Lycoris flavescens M. Kim \& S. T. Lee 붉노랑상사화 BS_20180631

\section{DIOSCOREACEAE 마과}

672. Dioscorea japonica Thunb. 참마 BS_20180888

673. Dioscorea nipponica Makino 부채마 BS_20180629 
Appendix 1. Continued.

674. Dioscorea polystachya Turcz. 마 BS_20180183

675. Dioscorea quinquelobata Thunb. 단풍마 BS_20180198

676. Dioscorea tenuipes Franch. \& Sav. 각시마 BS_20180334

PONTEDERIACEAE 물옥잠과

677. Monochoria vaginalis (Burm. f.) C. Presl var. plantaginea (Roxb.)

Solms 물달개비 $B S 20180558$

\section{IRIDACEAE 붓꽃과}

678. Iris koreana Nakai 노랑붓꽃 BS_20180071

679. Iris pseudacorus L. 노랑꽃창포* BS_20180453

$\star 680$. Iris rossii Baker var. latifolia J. K. Sim \& Y. S. Kim

넓은잎각시붓꽃 BS_20180450

\section{JUNCACEAE 골풀과}

681. Juncus decipiens (Buchenau) Nakai 골풀 BS_20180393 682. Juncus diastrophanthus Buchenau 별날개골풀 BS_20180618

$\star 683$. Juncus gracillimus (Buchenau) V. I. Krecz. \& Gontsch. 물골풀 BS 20180557

684. Juncus papillosus Franch. \& Sav. 청비녀골풀 BS_20180902

$\star 685$. Juncus setchuensis Buchenau 푸른갯골풀 BS_20180961

$\star 686$. Juncus tenuis Willd. 길골풀 BS 20180230

687. Luzula capitata (Miq. ex Franch. \& Sav.) Kom. 꿩의밥

BS 20180065

\section{COMMELINACEAE 닭의장풀과}

688. Aneilema keisak Hassk. 사마귀풀 BS_20180648

689. Commelina communis L. 닭의장풀 BS 20180473

690. Commelina communis L. var. angustifolia Nakai 좀닭의장풀

BS 20180850

\section{POACEAE 벼과}

691. Achnatherum pekinense (Hance) Ohwi 나래새 BS_20180440

692. Alopecurus aequalis Sobol. 뚝새풀 BS 20180520

693. Arthraxon hispidus (Thunb.) Makino 조개풀 BS_20180838

694. Arundinella hirta (Thunb.) Tanaka var. ciliata (Thunb.) Koidz. 새

BS_20180685

695. Avena fatua L. 메귀리 BS_20180540

696. Beckmannia syzigachne (Steud.) Fernald 개피 BS 20180364

$\star 697$. Brachypodium sylvaticum (Huds.) P. Beauv. 솦개밀 BS 20180738

698. Bromus catharticus Vahl 큰이삭풀 BS 20180930

699. Bromus japonicus Thunb. 참새귀리 $B S 20180158$

700. Calamagrostis arundinacea (L.) Roth 실새풀 BS 20180744

$\star$ 701. Calamagrostis epigejos (L.) Roth 산조풀 BS 20180215

$\star$ 702. Cleistogenes hackelii (Honda) Honda 대새풀 BS_20180479

703. Cymbopogon goeringii (Steud.) A. Camus 개솔새 $B S 20180354$

704. Dactylis glomerata L. 오리새 BS_20180124

$\star$ 705. Diarrhena fauriei (Hack.) Ohwi 광릉용수염 BS 20180400

706. Digitaria ciliaris (Retz.) Koeler 바랭이 BS_20180181

$\star$ 707. Digitaria radicosa (J. Presl) Miq. 좀바랭이 BS_20180855

708. Digitaria violascens Link 민바랭이 BS_20180264

709. Echinochloa crus-galli (L.) P. Beauv. 돌피 BS_20180496

710. Echinochloa crus-galli (L.) P. Beauv. var. echinatum (Willd.) Honda

물피 BS_20180566

$\star$ 711. Echinochloa crus-galli (L.) P. Beauv. var. praticola Ohwi 좀돌피 BS_20180851

712. Eleusine indica (L.) Gaertn. 왕바랭이 BS_20180218

713. Elymus ciliaris (Trin. ex Bunge) Tzvelev 속털개밀 BS_20180714

714. Elymus tsukushiensis Honda var. transiens (Hack.) Osada 개밀 BS 20180351

715. Eragrostis cilianensis (All.) Vignolo ex Janch. 참새그령 BS_20180892

716. Eragrostis curvula (Schrad.) Nees 능수참새그령 BS 20180465 717. Eragrostis ferruginea (Thunb.) P. Beauv. 그령 BS_20180407
Appendix 1. Continued.

718. Eragrostis multicaulis Steud. 비노리 BS_20180633

$\star$ 719. Eragrostis pilosa (L.) P. Beauv. 큰비노리 BS_20180924

720. Eriochloa villosa (Thunb.) Kunth 나도개피 BS_20180257

721. Festuca arundinacea Schreb. 큰김의털 BS_20180130

722. Imperata cylindrica (L.) Raeusch. 띠 BS_20180523

723. Isachne globosa (Thunb.) Kuntze 기장대풀 BS_20180417

724. Ischaemum anthephoroides (Steud.) Miq. 갯쇠보리 BS_20180373

$\star$ 725. Leersia japonica (Makino ex Honda) Honda 나도겨풀 BS 20180435

$\star$ 726. Leersia oryzoides (L.) Sw. 좀겨풀 BS_20180847

727. Leptochloa chinensis (L.) Nees 드렁새 BS_20180507

$\star$ 728. Leymus mollis (Trin.) Pilg. 갯그령 BS 20180084

729. Lolium multiflorum Lam. 쥐보리 BS_20180153

$\star$ 730. Lophatherum sinense Rendle 털조릿대풀 BS_20180320

731. Melica mutans L. 왕쌀새 BS 20180794

732. Melica onoei Franch. \& Sav. 쌀새 BS_20180746

733. Microstegium japonicum (Miq.) Koidz. 민바랭이새 BS 20180582

734. Microstegium vimineum (Trin.) A. Camus 나도바랭이새 BS_20180437

$\star$ 735. Microstegium vimineum (Trin.) A. Camus var. polystachyum

(Franch. \& Sav.) Ohwi 큰듬성이삭새 BS_20180918

$\star$ 736. Miscanthus sacchariflorus (Maxim.) Benth. \& Hool. f. ex

Franch. 물억새 BS_20180563

737. Miscanthus sinensis Andersson 참억새 BS 20180895

738. Miscanthus sinensis Andersson var. purpurascens (Andersson)

Matsum. 억새 BS_20180778

739. Muhlenbergia japonica Steud. 쥐꼬리새 BS_20180869

$\star 740$. Oplismenus burmanni (Retz.) P. Beauv. 민주름조개풀 BS_20180583

741. Oplismenus undulatifolius (Ard.) P. Beauv. 주름조개풀 BS 20180861

742. Panicum bisulcatum Thunb. 개기장 BS 20180345

743. Panicum dichotomiflorum Michx. 미국개기장 BS_20180568

$\star$ 744. Paspalum dilatatum Poir. 큰참새피 BS 20180932

745. Paspalum thunbergii Kunth ex Steud. 참새피 BS_20180211

746. Pennisetum alopecuroides (L.) Spreng. 수크령 BS_20180737

$\star$ 747. Phacelurus latifolius (Steud.) Ohwi 모새달 BS_20180550

748. Phaenosperma globosum Munro ex Benth. 산기장 BS_20180199

749. Phragmites australis (Cav.) Trin. ex Steud. 갈대 BS_20180335

750. Phragmites japonicus Steud. 달뿌리풀 BS_20180471

751. Phyllostachys nigra (Lodd. ex Lindl.) Munro var. henonis (Mitford)

Stapf ex Rendle 솜대* BS_20180717

752. Poa anпиa L. 새포아풀 BS_20180691

$\star$ 753. Polypogon monspeliensis (L.) Desf. 갯쇠돌피 BS 20180372

$\star$ 754. Sacciolepis indica (L.) Chase 좀물뚝새 BS_20180316

$\star$ 755. Sacciolepis indica (L.) Chase var. oryzetorum (Makino) Ohwi 물 뚝새 $B S 20180559$

756. Sasa borealis (Hack.) Makino \& Shibata 조릿대 BS_20180840

757. Schizachyrium brevifolium (Sw.) Nees ex Büse 쇠풀 BS 20180309

758. Setaria faberi R. A. W. Herrm. 가을강아지풀 BS_20180331

759. Setaria pumila (Poir.) Roem. \& Schult. 금강아지풀 BS_20180408

$\star 760$. Setaria pumila (Poir.) Roem. \& Schult. subsp. pallidefusca

(Schumach.) B. K. Simon 가는금강아지풀 BS_20180322

761. Setaria viridis (L.) P. Beauv. 강아지풀 BS_20180263

$\star 762$. Setaria viridis (L.) P. Beauv. subsp. pycnocoma (Steud.) Tzvelev 수강아지풀 $B S 20180727$

$\star$ 763. Setaria viridis (L.) P. Beauv. var. pachystachys (Franch. \& Sav.)

Masamura \& Nemoto 갯강아지풀 BS_20180288

$\star$ 764. Sorghum bicolor (L.) Moench 수수* BS 20180734

765. Spodiopogon cotulifer (Thunb.) Hack. 기름새 BS_20180415 
Appendix 1. Continued.

766. Spodiopogon sibiricus Trin. 큰기름새 BS_20180913 767. Sporobolus fertilis (Steud.) Clayton 쥐꼬리새풀 BS_20180870 768. Sporobolus piliferus (Trin.) Kunth 나도잔디 BS_20180306 769. Themeda triandra Forssk. 솔새 BS 20180210

770. Vulpia myuros (L.) C. C. Gmel. 들묵새 BS_20180511

771. Zoysia japonica Steud. 잔디 BS_20180827

772. Zoysia macrostachya Franch. \& Sav. 왕잔디 BS 20180795

\section{ARACEAE 천남성과}

$\star 773$. Arisaema amurense Maxim. 둥근잎천남성 BS 20180506

774. Arisaema ringens (Thunb.) Schott 큰천남성 BS 20180933

775. Arisaema serratum (Thunb.) Schott 점박이천남성 BS_20180833

776. Pinellia ternata (Thunb.) Makino 반하 BS 20180591

$\star 777$. Pinellia tripartita (Blume) Schott 대반하 BS_20180477

LEMNACEAE 개구리밥과

$\star 778$. Lemna perpusilla Torr. 좀개구리 밥 BS_20180845

$\star$ 779. Spirodela polyrrhiza (L.) Schleid. 개구리밥 BS_20180343

TYPHACEAE 부들과

780. Typha angustifolia L. 애기부들 BS_20180761

$\star$ 781. Typha latifolia L. 큰잎부들 BS_20180931

$\star 782$. Typha laxmannii Lepech. 꼬마부들 BS_20180425

783. Typha orientalis C. Presl 부들 BS_20180628

\section{CYPERACEAE 사초과}

$\star$ 784. Bolboschoenus fluviatilis (Torr.) Soják 큰매자기 BS_20180920

$\star$ 785. Bolboschoenus planiculmis (F. Schmidt) T. V. Egorova 좀매자기 BS_20180853

$\star$ 786. Bulbostylis densa (Wall.) Hand.-Mazz. 꽃하늘지기 BS 20180246

787. Carex aphanolepis Franch. \& Sav. 골사초 BS_20180392

788. Carex ciliato-marginata Nakai 털대사초 BS 20180941

789. Carex dimorpholepis Steud. 이삭사초 BS_20180814

$\star$ 790. Carex genkaiensis Ohwi 목포사초 BS_20180552

791. Carex gibba Wahlenb. 나도별사초 BS_20180438

$\star$ 792. Carex gifuensis Franch. 애기감둥사초 BS_20180752

793. Carex humilis Leyss. var. nana (H. Lév. \& Vaniot) Ohwi

가는잎그늘사초 BS_20180323

$\star$ 794. Carex kobomugi Ohwi 통보리사초 BS 20180079

795. Carex lenta D. Don 줄사초 BS_20180865

796. Carex neurocarpa Maxim. 갱이사초 BS_20180228

797. Carex okamotoi Ohwi 지리대사초 BS_20180875

$\star$ 798. Carex phacota Spreng. 비늘사초 $B S \_20180634$

$\star$ 799. Carex pumila Thunb. 좀보리사초 BS_20180081

$\star 800$. Carex scabrifolia Steud. 천일사초 BS_20180899

801. Carex siderosticta Hance 대사초 BS_20180478

802. Carex tristachya Thunb. 반들사초 $B S 20180589$

803. Cyperus amuricus Maxim. 방동사니 $B S \_20180593$

804. Cyperus difformis L. 알방동사니 BS_20180751

$\star$ 805. Cyperus haspan L. 모기방동사니 BS_20180549

806. Cyperus iria L. 참방동사니 BS_20180890

807. Cyperus microiria Steud. 금방동사니 BS_20180411

808. Cyperus orthostachyus Franch. \& Sav. 쇠방동사니 BS_20180723

$\star$ 809. Cyperus pacificus (Ohwi) Ohwi 흰방동사니 BS_20180986

$\star 810$. Fimbristylis autumnalis (L.) Roem. \& Schult. 애기하늘지기 BS_20180213

811. Fimbristylis dichotoma (L.) Vahl 하늘지기 BS_20180966

$\star 812$. Fimbristylis ferruginea (L.) Vahl 갯하늘지기 BS_20180286

813. Fimbristylis littoralis Gaudich. 바람하늘지기 BS_20180584

814. Fimbristylis tristachya R. Br. var. subbispicata (Nees \& Meyen) T.

Koyama 꼴하늘지기 BS_20180284

815. Kyllinga brevifolia Rottb. var. leiolepis (Franch. \& Sav.) H. Hara 파 대가리 BS_20180955
Appendix 1. Continued.

816. Schoenoplectiella triangulata (Roxb.) J. D. Jung \& H. K. Choi 송이 고랭이 BS_20180266

$\star 817$. Schoenoplectus juncoides (Roxb.) Palla 올챙 이고랭이 BS_20180790

$\star$ 818. Schoenoplectus tabernaemontani (C. C. Gmel.) Palla 큰고랭이 BS_20180248

819. Scirpus wichurae Boeck. 방울고랭이 BS_20180595

\section{ZINGIBERACEAE 생강과}

820. Zingiber mioga (Thunb.) Roscoe 양하 BS 20180774

\section{ORCHIDACEAE 난초과}

821. Amitostigma gracile (Blume) Schltr. 병아리난초 BS 20180620

$\star$ 822. Calanthe discolor Lindl. 새우난초 BS_20180689

823. Cephalanthera erecta (Thunb.) Blume 은난초 BS_20180808

824. Cephalanthera falcata (Thunb.) Blume 금난초 $B \bar{S} 20180410$

825. Cymbidium goeringii (Rchb. f.) Rchb. f. 보춘화 $B S 20180057$

^826. Liparis krameri Franch. \& Sav. 나나벌이난초 BS_20180434

827. Liparis kumokiri F. Maek. 옥잠난초 BS_20180787

828. Platanthera mandarinorum Rchb. f. 산제비란 BS_20180672 829. Spiranthes sinensis (Pers.) Ames 타래난초 BS_20180935 